ARTICLE

DOI: $10.1038 / s 41467-018-07109-w$

\title{
HLA-B57 micropolymorphism defines the sequence and conformational breadth of the immunopeptidome
}

Patricia T. Illing (1) 1, Phillip Pymm,2, Nathan P. Croft (10 1, Hugo G. Hilton ${ }^{3,4}$, Vladimir Jojic ${ }^{4}$, Alex S. Han, Juan L. Mendoza ${ }^{6,7}$, Nicole A. Mifsud ${ }^{1}$, Nadine L. Dudek${ }^{1}$, James McCluskey (1) ${ }^{8}$, Peter Parham ${ }^{3}$, Jamie Rossjohn (10) ${ }^{1,2,9}$, Julian P. Vivian ${ }^{1,2}$ \& Anthony W. Purcell (10 ${ }^{1}$

Immunophenotypic differences between closely related human leukocyte antigen (HLA) alleles have been associated with divergent clinical outcomes in infection, autoimmunity, transplantation and drug hypersensitivity. Here we explore the impact of micropolymorphism on peptide antigen presentation by three closely related HLA molecules, HLA-B`57:01, HLA$B \star 57: 03$ and HLA-B*58:01, that are differentially associated with the HIV elite controller phenotype and adverse drug reactions. For each allotype, we mine HLA ligand data sets derived from the same parental cell proteome to define qualitative differences in peptide presentation using classical peptide binding motifs and an unbiased statistical approach. The peptide repertoires show marked qualitative overlap, with 982 peptides presented by all allomorphs. However, differences in peptide abundance, HLA-peptide stability, and HLAbound conformation demonstrate that HLA micropolymorphism impacts more than simply the range of peptide ligands. These differences provide grounds for distinct immune reactivity and insights into the capacity of micropolymorphism to diversify immune outcomes.

\footnotetext{
${ }^{1}$ Infection and Immunity Program and Department of Biochemistry and Molecular Biology, Monash Biomedicine Discovery Institute, Monash University, Clayton, VIC 3800, Australia. ${ }^{2}$ Australian Research Council Centre of Excellence for Advanced Molecular Imaging, Monash University, Clayton, VIC 3800, Australia. ${ }^{3}$ Departments of Structural Biology and Microbiology \& Immunology, School of Medicine, Stanford University, Stanford 94305 CA, USA. ${ }^{4}$ Calico Life Sciences LLC, South San Francisco 94080 CA, USA. ${ }^{5}$ Department of Genetics, School of Medicine, Stanford University, Stanford 94305 CA, USA. ${ }^{6}$ Department of Molecular and Cellular Physiology, School of Medicine, Stanford University, Stanford 94305 CA, USA. ${ }^{7}$ Institute for Molecular Engineering and Department of Biochemistry \& Molecular Biology, University of Chicago, Chicago 60637 IL, USA. ${ }^{8}$ Department of Microbiology and Immunology, Peter Doherty Institute for Infection and Immunity, University of Melbourne, Parkville, VIC 3010, Australia. ${ }^{9}$ Institute of Infection and Immunity, Cardiff University School of Medicine, Heath Park, Cardiff CF14 4XN, UK. These authors contributed equally: Patricia T. Illing, Phillip Pymm. These authors jointly supervised this work: Julian P. Vivian, Anthony W. Purcell. Correspondence and requests for materials should be addressed to J.P.V. (email: julian.vivian@monash.edu) or to A.W.P. (email: anthony.purcell@monash.edu)
} 
$\mathrm{T}$ he human leucocyte antigen (HLA) molecules, encoded by the major histocompatibility complex (MHC) region of the genome, are cell surface glycoproteins responsible for the presentation of both endogenous and exogenously derived peptide antigens for immune surveillance. The introduction of novel complexes into this array, such as those containing peptides derived from invading pathogens, stimulates immune responses against infected cells. The genes encoding the HLA molecules (HLA-A, $-B$ and $-C$ for the classical HLA class I molecules, and $H L A-D P,-D Q$ and $-D R$ for the HLA class II molecules) are the most polymorphic of the human genome, with HLA-B alone possessing over 3000 functional allomorphs ${ }^{1}$. Sequence diversity in HLA class I molecules ranges from micropolymorphisms, which comprise just a few amino acids, to differences of more than 30 amino acids in more distantly related allomorphs. Peptides bind to HLA molecules via interactions between the side chains of anchor residues of the peptide and pockets within the antigen-binding cleft. In the HLA class I molecules, these pockets are denoted A-F, and a large part of their landscape is determined by polymorphic amino acid residues. These polymorphisms alter the stereo- and electrochemical environment of the pockets, dictating their ability to accommodate different peptide side chains thereby influencing the nature and quantity of peptides that are bound by a given HLA allomorph ${ }^{2-4}$. The nature of the peptide anchor residues accommodated by a particular HLA molecule is often referred to as the peptide-binding motif. Polymorphism further shapes the peptide array via impacting interactions with chaperones such as tapasin, which modulates peptide selection during peptide loading in the endoplasmic reticulum, biasing the peptide repertoire towards more stable ligands ${ }^{5,6}$.

Strikingly, polymorphism at a single amino acid in the antigenbinding cleft can cause divergent immune reactivity in many clinical scenarios. For example, ankylosing spondylitis is associated with some, but not all, HLA-B27 family members; for instance, HLA- $B^{\star} 27: 02,-B^{\star} 27: 03,-B^{\star} 27: 04$ and $-B^{\star} 27: 05$ confer risk, whilst micropolymorphic family members HLA- $B^{\star} 27: 06$ and $-B \star 27: 09$ do not $\left(\right.$ reviewed $\left.^{7}\right)$. Although the differential association of HLA-B27 allomorphs with ankylosing spondylitis has long been thought to be directly related to differences in ligandbinding characteristics, our recent studies have challenged this hypothesis, and show a more quantitative impact of micropolymorphism on the immunopeptidome rather than merely effects on ligand binding ${ }^{8,9}$. Similarly, abacavir hypersensitivity syndrome (AHS), a severe systemic hypersensitivity reaction to the antiretroviral drug abacavir and drug-induced liver injury mediated by the antibiotic flucloxacillin, are associated with HLA$B^{\star} 57: 01^{10,11}$, whilst the closely related HLA-B ${ }^{\star} 57: 03$, containing two amino acid substitutions in the antigen-binding cleft shows no association. Similarly, HLA-B ${ }^{\star} 58: 01$, possessing four substitutions in the antigen-binding cleft, shows no association with AHS ${ }^{12}$, but is instead strongly associated with allopurinol hypersensitivity ${ }^{13}$. It has been proposed that associations with adverse drug reactions are due to the unique ability of the associated HLA class I allomorph to present antigenic ligands, whether they be self-peptides, drug-modified peptides, or directly presented small-molecule drugs/metabolites ${ }^{14}$. However, whilst this view stands true for abacavir, which is uniquely accommodated within the antigen-binding cleft of HLA-B ${ }^{*} 57: 01$ in the vicinity of residues that are polymorphic between HLA-B*57:03 and HLA-B ${ }^{\star} 58: 01^{15,16}$, it may be too simplistic in the context of peptide presentation. For example, altered presentation of the same peptides by micropolymorphic allomorphs has been reported to impact immunogenicity and immunodominance hierarchies in the HLA-B35 family through altered plasticity and binding kinetics ${ }^{17,18}$, whilst distinct conformations of identical ligands presented by members of the HLA-B7 family are proposed to favour distinct escape mutations in human immunodeficiency virus $(\mathrm{HIV})^{19}$. Equally, a single residue can delineate tapasin dependence for peptide loading and define the susceptibility of an HLA molecule to viral interference with the peptide loading pathway ${ }^{5,20}$.

HLA-B57 family members are renowned for their association with the elite controller phenotype of HIV-infected individuals $^{21,22}$. The protective effect of HLA-B57 is hypothesised to be due to more efficient presentation of immunogenic HIV peptides to antiviral cytotoxic T lymphocytes than by nonprotective HLA variants (possessing disparate peptide-binding properties). However, despite the near-identical nature of the previously described HLA-ligand-binding motif within this family, a protective hierarchy is still evident and distinctions in Tcell response to HIV epitopes are manifest ${ }^{23}$. Moreover, despite similar modes of presentation by HLA-B ${ }^{\star} 57: 01$ and HLA$B \star 57: 03$, the immunodominant HIV-Gag-derived peptide KAFSPEVIPMF stimulates divergent $\mathrm{T}$-cell responses in the context of these two allomorphs, with HLA-B ${ }^{\star}$ 57:01 presentation generating a T-cell response able to recognise escape variant ${ }^{24,25}$.

These examples show the capacity for minor changes of the antigen-binding cleft to have marked effects on immune response and generate an impetus to understand more broadly the complexities of antigen presentation within the HLA-B57 family. HLA- ${ }^{\star} 57: 01$, HLA- ${ }^{\star}{ }^{\star 57: 03}$ and HLA- ${ }^{\star} 58: 01$ are micropolymorphic HLA allotypes of the HLA-B17 serotype. Polymorphism within these allotypes is focussed on regions of the antigen-binding cleft (cleft polymorphisms in comparison to HLA-B ${ }^{\star}$ 7:01: Asp114Asn and Ser116Tyr in HLA-B*57:03, and Met45Thr, Ala46Glu, Val97Arg and Val103Leu in HLA-B*58:01). Notably, residues 97,114 and 116 contribute to the E pocket of the antigen-binding cleft, whilst residue 116 also contributes to the $\mathrm{F}$ pocket. These are key locations of interaction between peptide ligands and the HLA heavy chain, with the F pocket accommodating the C-terminal anchor residue $(\mathrm{P} \Omega)$, and the $\mathrm{E}$ pocket interacting with $P \Omega-2$. The use of mass spectrometry to resolve binding preferences of single HLA allotypes is well established, and allows comparison of both micropolymorphic and distantly related molecules 8,26 .

Here we utilised a large database of constitutive peptide ligands isolated from HLA-B ${ }^{\star} 57: 01$, HLA-B ${ }^{\star} 57: 03$ and HLA-B ${ }^{\star} 58: 01^{15}$, to map micropolymorphism-dependent changes in the HLA peptide repertoire. Although speculated upon in many studies $^{27,28}$, our study formally shows that subtle differences in primary and secondary anchor preferences of each allomorph correlate with altered stability of the respective HLA-peptide (pHLA) complexes and altered conformation of common peptides within the antigen-binding cleft. The ability to resolve these key differences is crucial to understanding altered disease outcomes between individuals having closely related HLA molecules that can represent 'taboo mismatches' in clinical transplantation ${ }^{28,29}$.

\section{Results}

Qualitative resolution of the HLA peptide-binding motifs. To measure the impact of micropolymorphism on peptide presentation by HLA-B ${ }^{\star} 57: 01$, HLA- $\mathrm{B}^{\star} 57: 03$ and HLA-B ${ }^{\star} 58: 01$ (cleft polymorphism locations depicted in Fig. 1a, b, described as changes in comparison to HLA-B ${ }^{\star 57: 01}$ for $\mathrm{B}^{\star} 57: 03 / \mathrm{B}^{\star} 58: 01$ throughout the manuscript) we interrogated large monoallelic ligand data sets ( $>2500$ non-redundant peptide sequences) generated by isolation of naturally processed and presented HLA class I-bound peptides from individually transfected class I reduced $(\mathrm{C} 1 \mathrm{R}) \mathrm{cell}^{15}$. Of note, derivation from the same parental cell line ensured differences in peptide repertoire were 
a

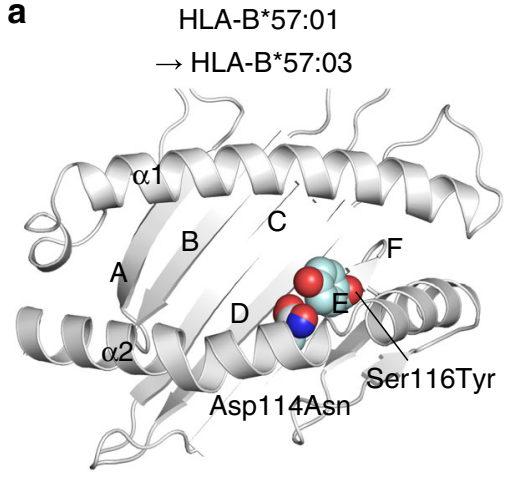

d

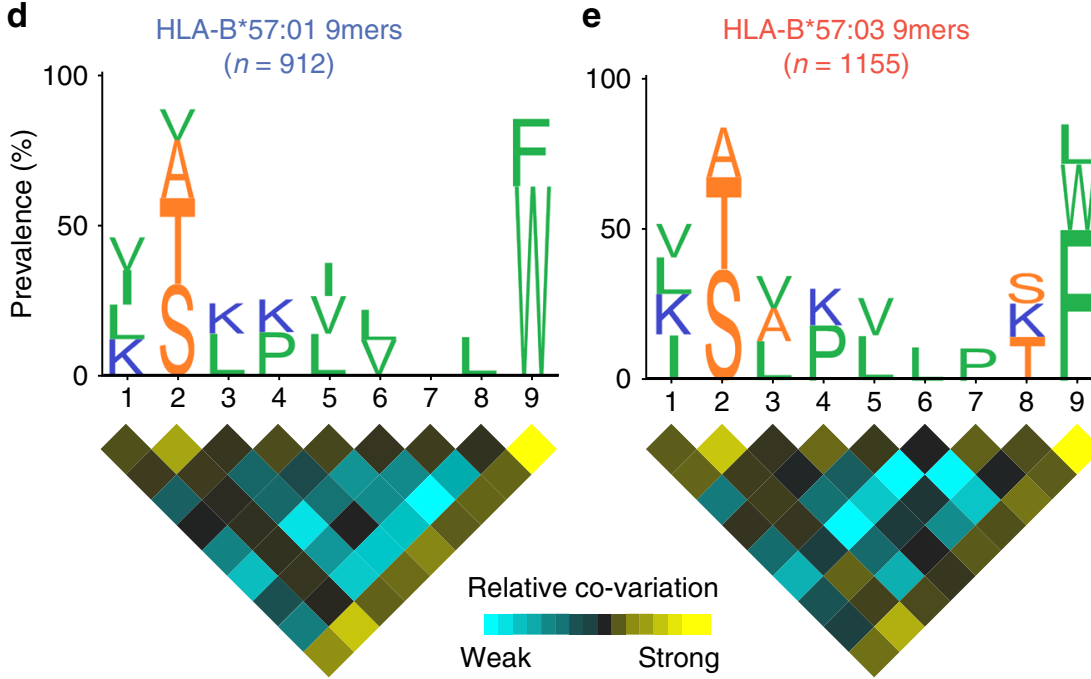

g

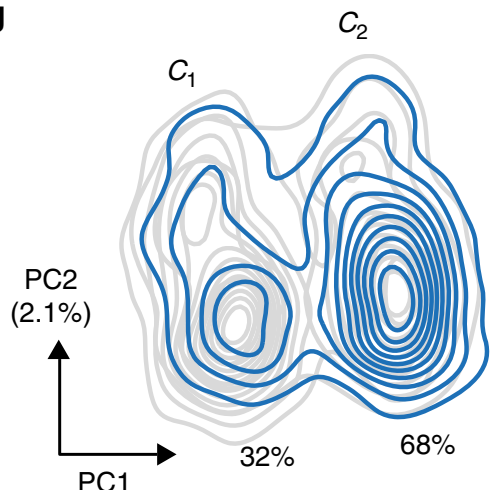

(2.3\%) b

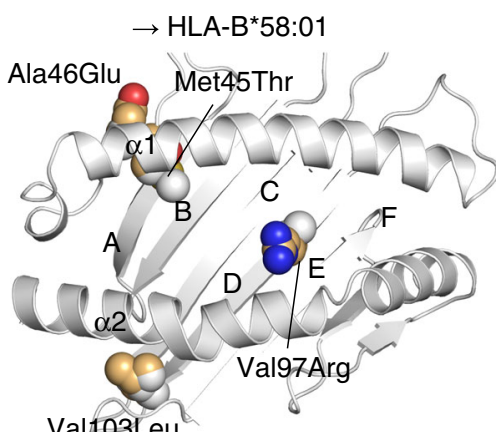

C

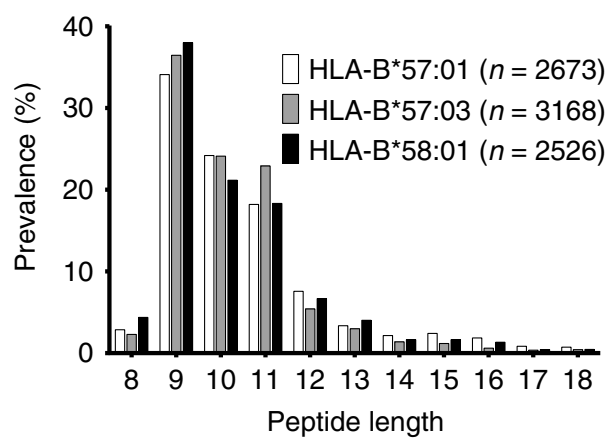

f

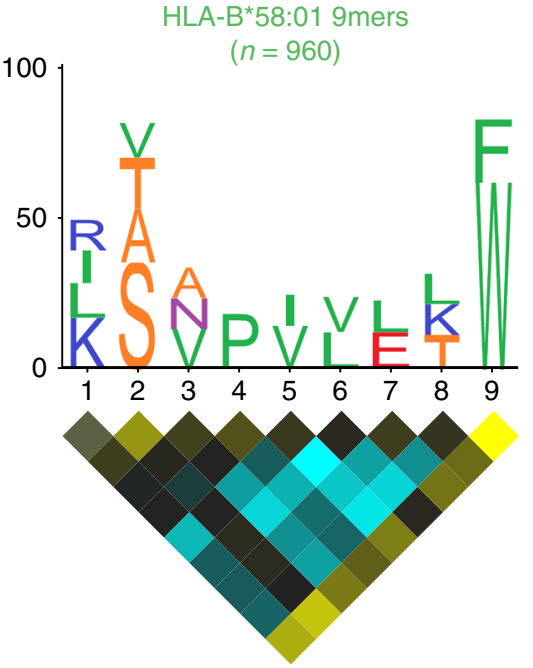

i

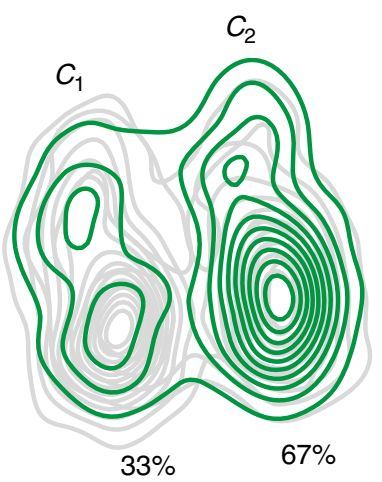

Fig. $1 \mathrm{HLA}-\mathrm{B}^{\star} 57: 01, \mathrm{HLA}-\mathrm{B}^{\star} 57: 03$ and $\mathrm{HLA}-\mathrm{B}^{\star} 58: 01$ sample peptides with similar physicochemical properties, but with different biases at the $C$ terminus. a, b Ribbon diagrams depicting the peptide-binding grooves of HLA-B*57:03 and HLA-B*58:01 compared to HLA-B*57:01 (polymorphic residues are shown as space-filled models). $\alpha 1$ and $\alpha 2$ helices and the positions of peptide-binding pockets $A-F$ are shown. $\mathbf{c}$ Length distributions of HLA-B $57: 01$ (clear bars), HLA-B ${ }^{\star} 57: 03$ (grey bars) and HLA-B ${ }^{\star} 58: 01$ (black bars) ligands across 8-18mers. d-f Sequence motifs of 9 mers for each allomorph with accompanying covariation heat maps, highlighting pairs of positions that are coupled. Amino acids are represented by single-letter code with height scaled to prevalence and colour representing small (orange), hydrophobic (green), polar (magenta), negatively charged (red) and positively charged (blue) residues. Only amino acids present with $10 \%$ or greater prevalence are depicted. $n$ is the number of 9 mer peptides within the data set. For the heat maps, square colour reflects the relative co-variation at, or between, each position in the peptide (aqua indicates weak co-variation and yellow indicates strong co-variation). $\mathbf{g}$-i Principal component analysis (PCA) density plots showing the distribution of 9mer peptides across PC1 and PC2 for HLA-B*57:01 (g), HLA-B*57:03 (h) and HLA-B ${ }^{\star}$ 58:01 (i). Coloured lines represent the named allomorph (HLA-B ${ }^{\star} 57: 01-b l u e, H L A-B^{\star} 57: 03-$ red and HLA-B ${ }^{\star} 58: 01-$ green) overlaid on the distribution of the remaining two allomorphs (grey lines). Two major clusters $\left(c_{1}\right.$ and $\left.c_{2}\right)$ were defined using $k$-means clustering $(k=2)$ with percentage of 9 mers within each cluster shown. Variation of PC1 and PC2 is shown in parentheses 
attributable to differences in determinant selection by the HLA allotypes and not the source proteome or polymorphisms within antigen-processing machinery.

Consistent with previously reported HLA class I ligands, peptides bound to the three HLA-B allotypes were predominantly 9-11 residues in length with a preference for nonamers (Fig. 1c, Supplementary Data 1). Sequence motifs, generated from nonredundant lists of all 9-11mers depict specific amino acid preferences at each position of the peptide ligand. These preferences are very similar for the three allotypes, which display bias for Ser (S), Thr (T), Ala (A) and to a lesser extent Val (V) at $\mathrm{P} 2$, and aromatic residues at the $\mathrm{C}$ terminus $(\mathrm{P} \Omega$ ) (Fig. $1 \mathrm{~d}-\mathrm{f}$, Supplementary Fig. 1a-c and 2a-c). Notably, whilst $\operatorname{Trp}(\mathrm{W})$ was the most prevalent $\mathrm{P} \Omega$ residue for HLA-B ${ }^{\star} 57: 01$ and HLA$\mathrm{B}^{\star} 58$ :01 ligands (62-80\% of 9-11mers), HLA- ${ }^{\star}{ }^{\star 57}$ :03-bound peptides showed a higher prevalence of Phe (F) $(43-50 \%$ Phe compared to $22-34 \%$ Trp across 9-11mers) (Supplementary Table 1, Fig. 1d-f, Supplementary Fig. 1a-c and 2a-c). In addition to traditional motif analysis, we also performed an unbiased statistical analysis of the allomorph-specific peptidomes using covariation analysis (Fig. $1 \mathrm{~d}-\mathrm{f}$ ). The $\mathrm{P} 2$ and $\mathrm{P} \Omega$ preferences were observed to exist as conserved pairings within peptides with Ser at P2 strongly paired with $\mathrm{P} \Omega$ Trp (HLA-B ${ }^{\star 57: 01}$ and HLA$\left.B^{\star} 58: 01\right)$ or Phe (HLA-B $\left.{ }^{\star} 57: 03\right)$ in 9 mers consistent with their nature as primary anchors (Supplementary Fig. 3).

In order to more deeply probe differences in ligand-binding characteristics, the physicochemical properties of each amino acid residue were used to independently compare the source of variation between the peptide repertoires. Each bound peptide was defined by a set of four parameters (in addition to 20 amino acid identity parameters) at each amino acid position: molecular weight, surface area, hydropathy index and isoelectric point. Consideration of broader physicochemical properties can capture similarities among amino acids that may be missed using traditional motif analysis ${ }^{30}$. Peptides of 9-11 residues in length that formed ligands of the three allotypes were then independently subjected to principal component analysis (PCA). For the three peptide lengths, the HLA ligands of each allotype were distributed asymmetrically across two distinct clusters defined by PC1 and PC2 (although further substructure was also observed for 9 and 11mers [Supplementary Fig. 4 and 5]). Although ligands mapped to both clusters for all variants, suggesting the potential to sample peptides of similar physicochemical properties, the bias of peptides between the clusters was inverted for HLA-B ${ }^{\star} 57: 03$ relative to HLA- $B^{\star} 57: 01$ and $-B^{\star} 58: 01$ (Fig. 1g-i, Supplementary Fig. $1 \mathrm{~d}-\mathrm{f}$ and $2 \mathrm{~d}-\mathrm{f}$ ). Parameters distinguishing these clusters include features of $P \Omega$, reflected by the enrichment of Phe in cluster $1\left(c_{1}\right)$ and Trp in cluster $2\left(c_{2}\right)$ of the 9mer PCA plots, demonstrating this location is the main point of difference among the repertoires (Supplementary Fig. 6 and 7). Features of P1 were major contributors to PC2 (and PC1 for 10 and 11mers), and distributed peptides within these major clusters in a similar fashion for all allotypes. In addition to the amino acid identity, the PCA provides additional insights into ligand selection by the different allomorphs. Importantly, a major driver of the PCA was the amino acid surface area at $\mathrm{P} \Omega$, which was not the case at $\mathrm{P} 2$ where hydropathy index was the most important property. This pattern was true for each of the three allotypes and was independent of peptide length.

In addition to the main anchor residues, HLA-B ${ }^{\star} 57: 01$ ligands showed a higher $\operatorname{Arg}(\mathrm{R})$, and to a lesser extent Lys (K), prevalence at $\mathrm{P} \Omega-2$ (i.e. $\mathrm{P} 7, \mathrm{P} 8$ and $\mathrm{P} 9$ of $9 \mathrm{mer}, 10 \mathrm{mer}$ and $11 \mathrm{mer}$ peptides, respectively), whilst HLA-B ${ }^{\star 58: 01}$ ligands displayed greater $\mathrm{P} \Omega-2$ Glu (E) (Fig. 1d-f, Supplementary Fig. 1a-c and 2a-c, Supplementary Table 2). We therefore hypothesised that $\mathrm{P} \Omega-2$ is a secondary anchor site, shaped by polymorphic residues
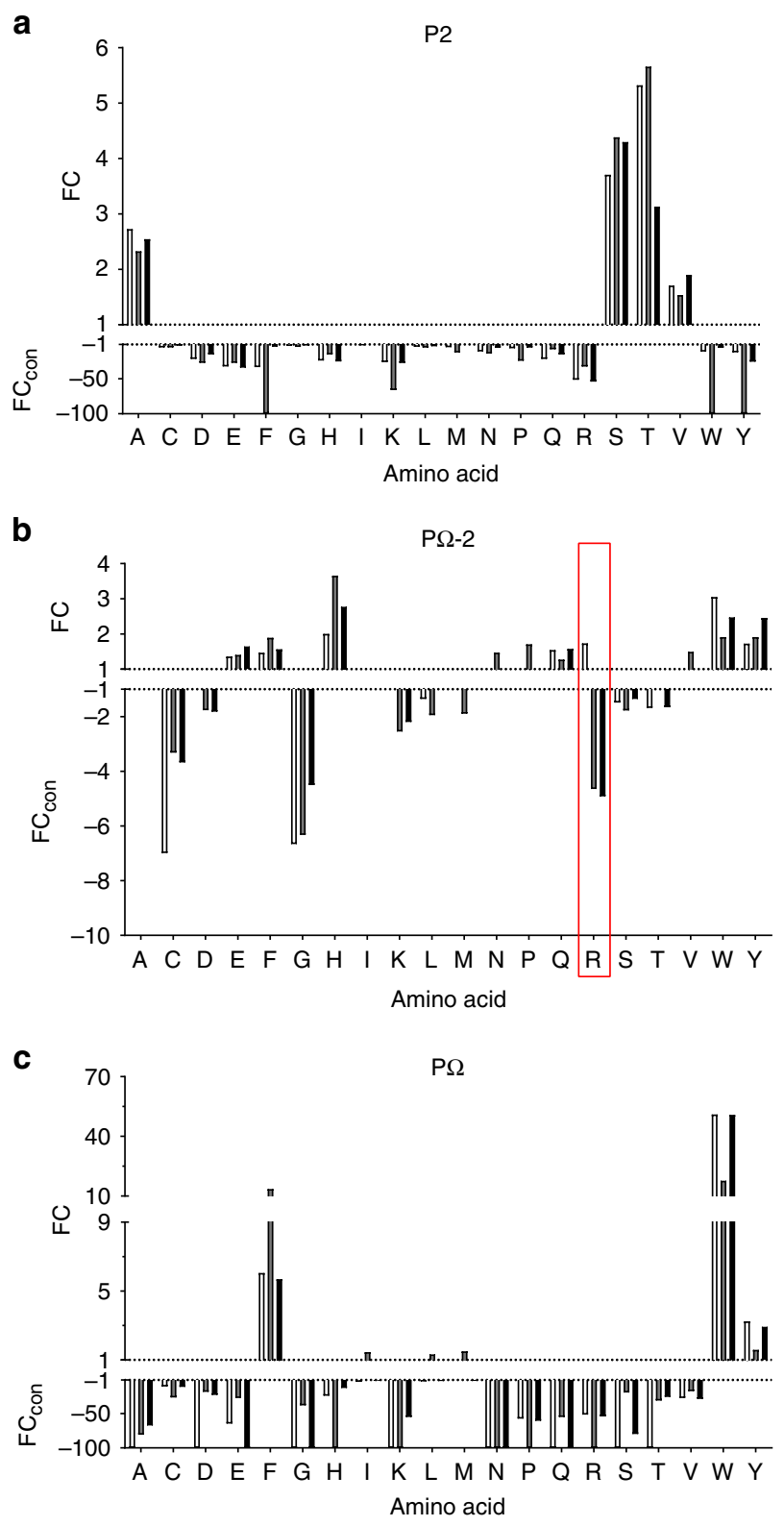

Fig. 2 Enrichment/diminution of residues at $P 2, P \Omega-2$ and $P \Omega$ of HLA-B57 family ligands distinguish primary and secondary anchor sites. The enrichment of specific residues at $P 2(\mathbf{a}), P \Omega-2(\mathbf{b})$ and $P \Omega(\mathbf{c})$ of all 9 residue peptide binders of HLA-B*57:01 (clear bars, 912 peptides), HLA$B \star 57: 03$ (grey bars, 1155 peptides) and HLA-B*58:01 (black bars, 960 peptides) identified by LC-MS/MS relative to amino acid frequencies in the human proteome. Deviations in prevalence from the human proteome are depicted as either a fold change (FC, for amino acids at higher prevalence than in the human proteome) or a converted $F C$ ( $F C_{\text {con }}=-1 / F C$, for amino acids present at lower prevalence than in the human proteome), as determined using iceLogo v1.2 stand-alone software ${ }^{31}$ using the static reference method (reference set Homo sapiens Swiss-Prot means, $p<0.05$ ). $\mathrm{FC}>1$ indicates enrichment, $\mathrm{FC}_{\mathrm{con}}<-1$ indicates disfavoured residues, -100 indicates absence. In $\mathbf{b}$ the unique enrichment of $\operatorname{Arg}(R)$ at $P \Omega-2$ by HLA- $B^{\star} 57: 01$ is highlighted by the red box

of the E pocket (Fig. 1a, b). Consequently, to probe the nature of the anchor sites more stringently we assessed enrichment of amino acid use at a particular location relative to global prevalence in the human proteome using icelogo software ${ }^{31}$ (iceLogo v1.2, static reference method, Homo sapiens Swiss-prot 


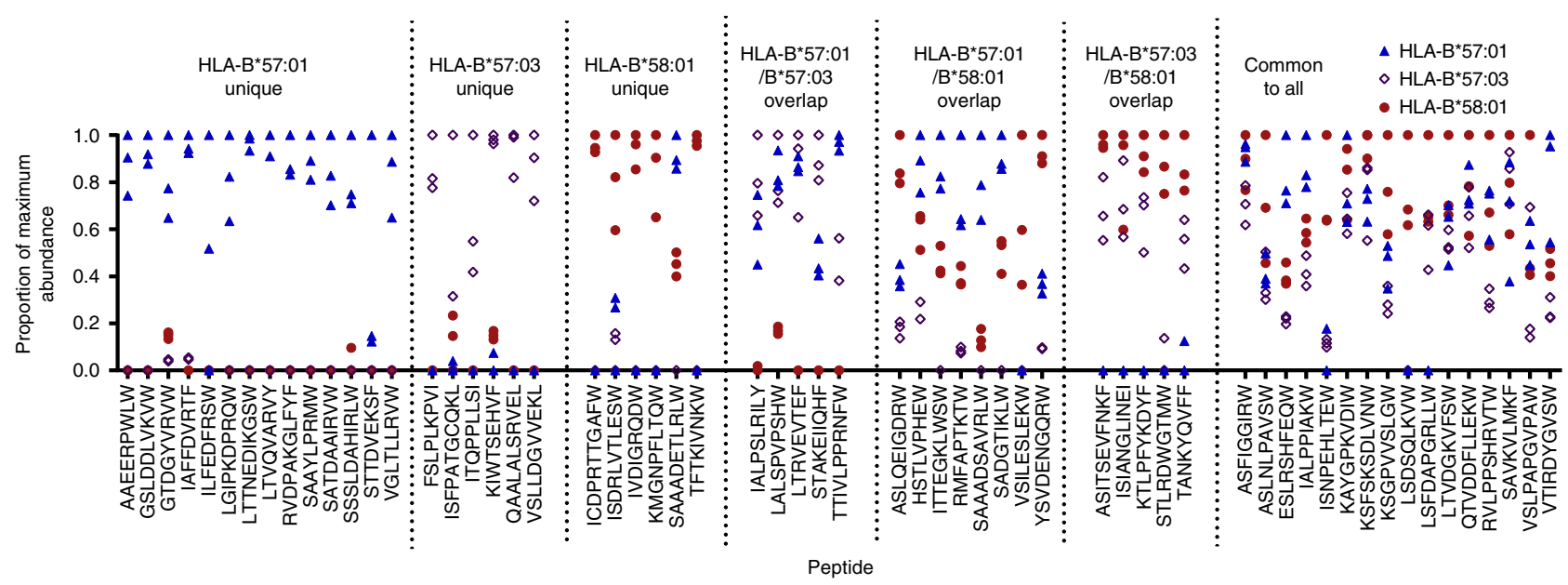

Fig. 3 MRM analysis reveals quantitative differences in peptide presentation and suggests greater overlap in peptide repertoire. Relative abundance of

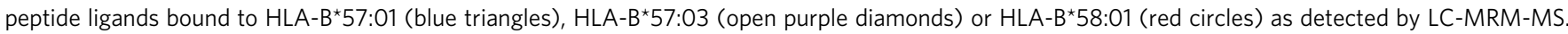
Peptides are categorised based on previous detection by LC-MS/MS as either binding a single HLA allotype (unique), two HLA allotypes (overlap) or all three HLA allotypes (common). On peptide detection the combined peak area for all MRM transitions, normalised against co-immunoprecipitated $\beta_{2} \mathrm{~m}$, was used to calculate relative abundance. Abundances are shown as a proportion of the maximum normalised peak area detected for the peptide across all experiments. Data are shown for three biological replicate experiments per allotype

means, $p<0.05)$. Enrichment was depicted as a fold change $(\mathrm{FC})$ in prevalence at primary anchor locations $\mathrm{P} 2$ and $\mathrm{P} \Omega$, and the potential secondary anchor site $P \Omega-2$, for 9mer peptides (Fig. 2). At both $\mathrm{P} 2$ and $\mathrm{P} \Omega$, strong enrichment of a small subset of amino acids (Ala, Ser, Thr and Val for P2 and Phe, Trp and Tyr for P $\Omega$ ) was displayed whilst other amino acids were disfavoured (i.e. less prevalent than in the human proteome, depicted as converted FC $\left.\left[\mathrm{FC}_{\text {con }}\right]\right)$. This was particularly evident at $\mathrm{P} \Omega$, although HLA$B^{\star}$ 57:03 showed some enrichment of Leu, Ile and Met in addition to aromatic residues (Fig. 2c). In contrast with the primary anchor sites, no amino acids were strongly disfavoured at $P \Omega-2$. However, enrichment of Arg was a distinct feature of HLA$\mathrm{B}^{\star} 57: 01$ (FC 1.73), compared to HLA-B ${ }^{\star} 57: 03\left(\mathrm{FC}_{\mathrm{con}}-4.65\right)$ and HLA-B ${ }^{\star} 58: 01\left(\mathrm{FC}_{\mathrm{con}}-4.92\right)$ (Fig. $2 \mathrm{~b}$, red box). Lys at $\mathrm{P} \Omega-2$, though not significantly enriched for HLA-B ${ }^{\star} 57: 01$ (FC 1.07, $p$ > $0.05)$, was disfavoured by HLA-B ${ }^{\star} 57: 03\left(\mathrm{FC}_{\mathrm{con}}-2.55\right)$ and $\mathrm{B}^{\star} 58: 01\left(\mathrm{FC}_{\mathrm{con}}-2.20\right)$. Although most prevalent in the repertoire of HLA-B ${ }^{\star} 58: 01$, Glu was enriched at $P \Omega-2$ for all allotypes (FC 1.36-1.65). Pro showed enrichment at $P \Omega-2$ for HLA-B ${ }^{\star} 57: 03$ alone (FC 1.71), and was present in $>10 \%$ of 9 mer ligands of this allomorph, however this was not the case for 10 and $11 \mathrm{mer}$ peptides (Figs. 1d-f and 2b, Supplementary Fig. 1, 2). Collectively, these data resolve three distinct peptide-binding motifs based on the physicochemical properties and amino acid occupancy at different positions of the bound peptide ligand.

Quantitative differences in presentation of common peptides. As anticipated there is a large overlap in peptide ligands presented with 982 peptides (by sequence alone) common to all three HLA-B allotypes (26-33\% of the allotypic repertoire), increasing to 1361-1546 (38-51\%) between allotype pairs (Supplementary Data 2). During tandem mass spectrometry (MS/MS) analysis, high quality of sequencing data was achieved by limiting fragmentation to the 30 most abundant species observed per second ${ }^{15}$. This selection resulted in the potential to miss lessabundant ions, especially in chromatographic regions of high complexity. Thus, it is likely that some of the peptides identified as unique to a particular allotype by liquid chromatography (LC)MS/MS-based peptide identification were present at low concentrations in eluates from the other allotypes and as such failed to be selected for MS/MS.
Targeted LC-MS techniques such as multiple reaction monitoring (MRM) have been used to detect both high and low abundance ligands in highly complex samples eluted from the MHC and allow comparison of abundance ${ }^{32,33}$. Therefore, we designed an LC-MRM-MS approach to assess whether peptides were identified as unique to a particular allotype due to sampling issues rather than binding specificity. To this purpose, we generated a representative list containing 60 native peptides from those identified by MS/MS in biological replicate experiments for a given allotype and could be identified in eluates from $10^{8}$ cells of at least one allotype. These peptides were selected from each of the following categories: unique to an allotype, common to all allotypes or common to two of the three allotypes. Three new independent biological replicates were analysed per allotype by LC-MRM-MS and individual peptide relative abundance determined across samples.

Using this sampling independent approach 5/17, 7/28 and 6/25 (3/17, $7 / 28$ and 5/25 in multiple replicates) of the peptides not previously identified in eluates from HLA-B ${ }^{\star} 57: 01$, HLA-B ${ }^{\star} 57: 03$ and HLA-B ${ }^{\star 58: 01}$ respectively were detected, generally at considerably lower relative abundance than for the allotypes for which they were initially described as ligands (Fig. 3), supporting the rationale for this targeted approach. Indeed, although only identified with a deaminated Arg at P9 in the immunopeptidome of HLA-B ${ }^{\star} 57: 01$ by LC-MS/MS (confidence $95,>5 \%$ false discovery rate (FDR), Supplementary Data 2), native SAAADETLRLW contributed most to the immunopeptidome of this allotype. Quantitative differences across the allotypes were observed for all peptides, even those that were consistently isolated from all three allotypes in the original non-targeted LCMS/MS experiments, implying quantitative, as much as qualitative, differences distinguish the immunopeptidomes of these closely related allotypes.

$\mathbf{P} \Omega$ and $\mathbf{P} \Omega-2$ preferences correlate with pHLA stability. Given the differences in $P \Omega$ and $P \Omega-2$ anchor preferences, we examined the impact of these residues on pHLA complex stability. To do so we chose two 9mers containing Arg/Lys at P7 (P $\Omega-2)$ that formed a natural part of the HLA-B ${ }^{\star 57: 01}$ peptide repertoire, LSSPVTKSF and LTVQVARVY, and designed P7/9 variants, to utilise in thermal stability experiments. LSSPVTKSF was also 
Table 1 The impact of $P \Omega-2$ and $P \Omega$ peptide residue substitutions on HLA-peptide complex thermal stability

\begin{tabular}{|c|c|c|c|c|c|c|c|c|c|c|c|c|}
\hline Peptide sequence & $\begin{array}{l}\text { HLA-B } \star 57: 01 \\
T_{m}\left({ }^{\circ} \mathrm{C}\right)\end{array}$ & $P \Omega-2 Q$ & $P \Omega W$ & $\mathbf{x}$ & $\begin{array}{l}\text { HLA-B }{ }^{\star} 57: 03 \\
T_{m}\left({ }^{\circ} \mathrm{C}\right)\end{array}$ & $\begin{array}{l}P \Omega-2 \\
Q\end{array}$ & $P \Omega W$ & $\mathbf{x}$ & $\begin{array}{l}\text { HLA-B }{ }^{\star} 58: 01 \\
T_{m}\left({ }^{\circ} \mathrm{C}\right) \\
\end{array}$ & $\begin{array}{l}P \Omega-2 \\
Q\end{array}$ & $P \Omega W$ & $\mathbf{x}$ \\
\hline LSSPVTKSF (wt) & $70.6(0.74)$ & -0.2 & 2.0 & & $69.2(0.35)$ & 0.4 & 1.8 & & $69.3(0.52)$ & 0.9 & 2.5 & \\
\hline LSSPVTQSF & $70.4(0.26)$ & - & 2.7 & & $69.6(0.11)^{a}$ & - & 1.5 & & $70.2(0.7)$ & - & 2.8 & \\
\hline LSSPVTQSW & $73.1(0.18)^{a}$ & - & - & & $71.1(0.1)$ & - & - & & $73.0(0.32)$ & - & - & \\
\hline LTVQVARVY (wt) & $69.4(0.18)^{a}$ & -2.3 & 2.8 & $x$ & $60.6(0.67)$ & 2.5 & 8.6 & $x$ & N.D. & - & - & \\
\hline LTVQVAQVY & $67.1(0.18)^{a}$ & $\overline{-}$ & 3.9 & & $63.1(0.14)$ & - & 7.8 & & N.D. & - & - & \\
\hline
\end{tabular}

Thermal stability is reported as mean temperature for $50 \%$ unfold $\left(T_{\mathrm{m}}\right)$, standard deviation is shown in parentheses. Values are calculated from duplicates at $1 \mathrm{mg} \mathrm{mL}^{-1}$ protein and $0.5 \mathrm{mg} \mathrm{mL} \mathrm{protein}^{-1}$ ( 4 total) unless indicated otherwise. The impact of the $P \Omega-2$ to $Q$ and $P \Omega$ to $W$ on $T_{m}$ are shown where applicable (' - ' is placed where not applicable), changes of magnitude $>1{ }^{\circ} \mathrm{C}$ are underlined (decreased stability) or in bold (increased stability). Column $X$ denotes complexes for which structures were solved using $X$-ray crystallography

ND not determined due to poor HLA-peptide refold

avalues calculated from duplicates at $0.5 \mathrm{mg} \mathrm{mL}^{-1}$ protein alone

b Values calculated from duplicates at 0.8 and $0.5 \mathrm{mg} \mathrm{mL}^{-1}$ protein

'Values calculated from quadruplicates at 1 and $0.5 \mathrm{mg} \mathrm{mL}^{-1}$ protein

identified in the repertoires of HLA-B ${ }^{\star} 57: 03$ and HLA-B ${ }^{\star 58: 01}$ by LC-MS/MS, and the structure of LSSPVTKSF in complex with HLA-B ${ }^{\star}$ 57:01 has been published previously, showing a saltbridge between P7Lys and Asp114 of the HLA-B`57:01 heavy chain (PDB 2RFX) ${ }^{34}$. LTVQVARVY was not detected in the repertoire of HLA-B ${ }^{\star 57: 03}$ or HLA-B ${ }^{\star} 58: 01$ (Fig. 3 ).

LTVQVARVY complexes were markedly more stable in the context of HLA-B ${ }^{\star 57: 01}$ than HLA-B ${ }^{\star 57: 03}\left(\sim 9{ }^{\circ} \mathrm{C}\right.$ difference in temperature for $50 \%$ unfold $\left[T_{\mathrm{m}}\right]$, Table 1$)$. Consistent with the enrichment of P7Arg by HLA-B ${ }^{\star} 57: 01$ alone, the P7Gln mutation (chosen due to similar enrichment of this residue at $\mathrm{P} 7$ by all allotypes, Fig. 2b) reduced this difference to $\sim 4{ }^{\circ} \mathrm{C}$ by increasing the stability of HLA-B ${ }^{\star}$ 57:03 complexes and reducing the stability of HLA-B ${ }^{\star}$ 57:01 complexes. In contrast, the substitution of the P9Tyr for Trp, which is more enriched at this location in ligands of both allotypes, improved the stability of both HLA-B ${ }^{\star 57: 01}$ $\left(+2.8^{\circ} \mathrm{C}\right)$ and HLA-B ${ }^{\star} 57: 03\left(+8.6^{\circ} \mathrm{C}\right)$ complexes. The P7Gln mutation had less impact in the context of P9Trp $\left(<2{ }^{\circ} \mathrm{C}\right)$ for both HLA-B ${ }^{\star} 57: 01$ and HLA-B ${ }^{\star} 57: 03$ but increased the stability of HLA-B ${ }^{\star} 58: 01$ complexes $\left(+4.6^{\circ} \mathrm{C}\right)$, consistent with disfavoured P7Arg by HLA-B ${ }^{\star} 58: 01$ (Fig. 2b).

For pHLA containing LSSPVTKSF, the impacts of P7/ P9 substitutions were less pronounced. For all allotypes mutation of the P7Lys to Gln had marginal impact on the $T_{\mathrm{m}}\left(<1{ }^{\circ} \mathrm{C}\right)$, although the P9Phe to Trp mutation showed a trend towards stabilising all complexes $\left(+1.8-2.5^{\circ} \mathrm{C}\right)$. Introduction of the P7Gln mutation also had minimal impact in the context of P9Trp mutation. The reduced influence of the P7Lys to Gln mutation is consistent with the weaker enrichment/diminution of P7Lys as compared to P7Arg displayed by each allotype (Fig. 2b). Similarly, all allotypes show less selective discrimination between Phe and Trp at P9 than between Tyr and Trp (Fig. 2c), consistent with a smaller impact of mutation of P9 to Trp in the context of LSSPVTKSF compared to LTVQVARVY.

SAAADETLRLW, detected in the repertoire of HLA-B ${ }^{\star} 58: 01$ (MS/MS and MRM) and HLA-B ${ }^{\star 57: 01 ~(M R M ~ o n l y) ~ a s ~ d e s c r i b e d ~}$ above, was also subject to thermal stability assays. The trend in thermal stability across the allomorphs (HLA-B ${ }^{\star} 57: 01\left[67.5^{\circ} \mathrm{C}\right]>$ HLA-B ${ }^{\star} 58: 01\left[64.4^{\circ} \mathrm{C}\right]>$ HLA-B ${ }^{\star} 57: 03\left[61.3^{\circ} \mathrm{C}\right]$, Table 1$)$ correlated with the relative abundance detected in their repertoires by MRM (HLA-B ${ }^{\star 57: 01 ~>~ H L A-B ~}{ }^{\star 58: 01 ~>~ H L A-B ` 57: 03, ~ F i g . ~ 3) . ~}$

Conformations of common ligands differ between allomorphs. To understand the structural effects of micropolymorphism between HLA-B ${ }^{\star 57: 01, ~ H L A-B}{ }^{\star 57: 03}$ and HLA-B ${ }^{\star 58: 01}$ and its relationship to peptide association, crystal structures in complex with the peptides LTVQVARVW, LTVQVARVY and LSSPVTKSW were determined to resolutions of 1.6-2.0 $\AA$ (data collection and refinement statistics summarised in Table 2). The high quality of the resultant models allowed for direct and reliable comparison of the structures (Supplementary Fig. 8). The three HLA molecules had similar overall tertiary structures for each peptide complex (root mean square deviation values ranging from 0.16 to $0.51 \AA$ over $C a$ positions for residues $1-175$ ) and there were no significant deviations in the secondary structure elements of the peptide-binding cleft (Supplementary Fig. 9). As such, the differential peptide-binding preferences were not due to any gross structural differences but rather to subtle differences in the architecture of the peptide-binding pockets.

The three HLA molecules are differentiated by polymorphisms distributed across the length of the peptide-binding groove (Fig. 1a, b). As a consequence of these substitutions the C, D, E and $F$ pockets of HLA-B ${ }^{\star 57: 01}$ were the deepest and most negatively charged of the three allomorphs (Fig. 4a). HLA$B \star 58: 01$ had the most shallow $C$ and $D$ pockets and $B \star 57: 03$ the shallowest $\mathrm{E}$ and $\mathrm{F}$ pockets (Fig. $4 \mathrm{~b}, \mathrm{c}$ ). Peripheral to the peptidebinding groove are further substitutions at positions Ala46Glu and Val103Leu (Fig. 1b) that subtly affect the structure of the $\beta 3$ $\beta 4$ and $\beta 5-\beta 6$ loops respectively (Supplementary Fig. 9). However, it should be noted that the location of these peripheral polymorphisms suggests that they are unlikely to directly influence $\mathrm{T}$-cell receptor (TCR) recognition. These observations are consistent with the shared $\mathrm{P} 2$ anchor preference across the allomorphs, whilst the shallower $F$ pocket of HLA-B ${ }^{\star}$ 57:03 correlates with greater permissiveness for Phe and smaller nonaromatic anchors at $\mathrm{P} \Omega$ (Fig. 2c) and the reduction in preference for high amino acid surface area at $P \Omega$ in the PCA. Whilst differences in $\mathrm{F}$ pocket architecture did not impact upon the conformation of Phe and Trp residues at P $\Omega$, Tyr116 of HLA$B \star 57: 03$ restricted the accommodation of the hydroxyl group of $\mathrm{P} \Omega$ Tyr, illustrated by a $1.4 \AA$ shift of this group observed between HLA-B ${ }^{\star}$ 57:01-LTVQVARVY and HLA-B ${ }^{\star 57: 03-L T V Q V A R V Y ~}$ structures (Fig. 4f).

Notwithstanding the differences at the $\mathrm{F}$ pocket, the more striking differences in peptide conformation appear to be engendered by the respective $\mathrm{D}$ and $\mathrm{E}$ pocket environments. The depth and negative charge of the $\mathrm{D}$ and $\mathrm{E}$ pockets of HLA$\mathrm{B}^{\star 57: 01}$ accommodated the Arg and Lys residues at the P $\Omega-2$ position of LTVQVARVW and LSSPVTKSW with the guanidino-head group of the Arg bound deeply within the $\mathrm{E}$ pocket, interacting with Asp114 (Fig. 4d, e, g). HLA-B ${ }^{\star}$ 58:01 was similarly able to accommodate Arg and Lys residues within the $\mathrm{E}$ 
Table 2 Data collection and refinement statistics

\begin{tabular}{|c|c|c|c|c|c|c|c|c|}
\hline & $\begin{array}{l}\text { HLA-B`57:01- } \\
\text { LTVQVARVY }\end{array}$ & $\begin{array}{l}\text { HLA-B`57:01- } \\
\text { LTVQVARVW }\end{array}$ & $\begin{array}{l}\text { HLA-B`57:01- } \\
\text { LSSPVTKSW }\end{array}$ & $\begin{array}{l}\text { HLA-B`57:03- } \\
\text { LTVQVARVY }\end{array}$ & $\begin{array}{l}\text { HLA-B`57:03- } \\
\text { LTVQVARVW }\end{array}$ & $\begin{array}{l}\text { HLA-B`57:03- } \\
\text { LSSPVTKSW }\end{array}$ & $\begin{array}{l}\text { HLA-B`58:01- } \\
\text { LTVQVARVW }\end{array}$ & $\begin{array}{l}\text { HLA-B`58:01- } \\
\text { LSSPVTKSW }\end{array}$ \\
\hline \multicolumn{9}{|l|}{ Data collection statistics } \\
\hline Temperature (K) & 100 & 100 & 100 & 100 & 100 & 100 & 100 & 100 \\
\hline X-ray source & $\begin{array}{l}\text { MX2 Australian } \\
\text { synchrotron }\end{array}$ & $\begin{array}{l}\text { MX2 Australian } \\
\text { synchrotron }\end{array}$ & $\begin{array}{l}\text { MX2 Australian } \\
\text { synchrotron }\end{array}$ & $\begin{array}{l}\text { MX2 Australian } \\
\text { synchrotron }\end{array}$ & $\begin{array}{l}\text { MX2 Australian } \\
\text { synchrotron }\end{array}$ & $\begin{array}{l}\text { MX2 Australian } \\
\text { synchrotron }\end{array}$ & $\begin{array}{l}\text { MX2 Australian } \\
\text { synchrotron }\end{array}$ & $\begin{array}{l}\text { MX2 Australian } \\
\text { synchrotron }\end{array}$ \\
\hline Space group & $P 2_{1} 2_{1} 2_{1}$ & $P 2_{1} 2_{1} 2_{1}$ & $P 2_{1} 2_{1} 2_{1}$ & $P 2_{1} 2_{1} 2_{1}$ & $P 2_{1} 2_{1} 2_{1}$ & $P 2_{1} 2_{1} 2_{1}$ & $P 2_{1} 2_{1} 2_{1}$ & $P 2_{1} 2_{1} 2_{1}$ \\
\hline Cell dimensions & $\begin{array}{l}a=50.4, b= \\
81.5, c=109.0\end{array}$ & $\begin{array}{l}a=50.7, b= \\
81.8, c=109.3\end{array}$ & $\begin{array}{l}a=50.6, b= \\
81.6, c=110.3\end{array}$ & $\begin{array}{l}a=50.8, b= \\
81.8, c=109.5\end{array}$ & $\begin{array}{l}a=50.9, b= \\
81.9, c=109.8\end{array}$ & $\begin{array}{l}a=50.6, b= \\
81.8, c=110.0\end{array}$ & $\begin{array}{l}a=50.0 b= \\
81.9, c=110.1\end{array}$ & $\begin{array}{l}a=50.7, b= \\
81.8, c=109.7\end{array}$ \\
\hline Resolution $(\AA)$ & $\begin{array}{l}50-1.90 \\
(2.00-1.90)\end{array}$ & $\begin{array}{l}50-1.80 \\
(1.90-1.80)\end{array}$ & $\begin{array}{l}50-2.00 \\
(2.11-2.00)\end{array}$ & $\begin{array}{l}50-1.80 \\
(1.90-1.80)\end{array}$ & $\begin{array}{l}50-1.80 \\
(1.90-1.80)\end{array}$ & $\begin{array}{l}50-2.00 \\
(2.11-2.00)\end{array}$ & $\begin{array}{l}50-2.00 \\
(2.11-2.00)\end{array}$ & $\begin{array}{l}50-1.60 \\
(1.69-1.60)\end{array}$ \\
\hline Total no. of observations & $\begin{array}{l}240990(34 \\
763)\end{array}$ & $\begin{array}{l}234376(34 \\
331)\end{array}$ & $\begin{array}{l}231704(33 \\
624)\end{array}$ & $\begin{array}{l}234123(33 \\
600)\end{array}$ & $\begin{array}{l}283895(40 \\
374)\end{array}$ & $\begin{array}{l}170623(24 \\
847)\end{array}$ & $170326(24582)$ & $\begin{array}{l}438590(60 \\
847)\end{array}$ \\
\hline No. of unique observations & $36221(5213)$ & $42942(6172)$ & 31727 (4561) & $42970(6161)$ & $43277(6224)$ & 31614 (4559) & $31297(4468)$ & 60877 (8687) \\
\hline Multiplicity & $6.7(6.7)$ & $5.5(5.6)$ & $7.3(7.4)$ & $5.4(5.5)$ & $6.6(6.5)$ & $5.4(5.5)$ & $5.4(5.5)$ & $7.2(7.0)$ \\
\hline Data completeness (\%) & $100(100)$ & $100(100)$ & $100(100)$ & $99.9(99.7)$ & $99.8(99.4)$ & $99.9(100)$ & $99.9(100)$ & $99.7(98.7)$ \\
\hline $1 / \sigma_{1}$ & $9.7(3.1)$ & $12.4(3.7)$ & $12.6(3.2)$ & $9.5(3.4)$ & $10.1(2.7)$ & $10.2(3.7)$ & $8.3(2.8)$ & $22.7(4.3)$ \\
\hline $\begin{array}{l}R_{\text {merge }}{ }^{a} \\
\text { Refinement statistics }\end{array}$ & $0.16(0.61)$ & $0.10(0.51)$ & $0.16(0.70)$ & $0.14(0.71)$ & $0.14(0.74)$ & $0.14(0.49)$ & $0.18(0.61)$ & $0.058(0.467)$ \\
\hline \multicolumn{9}{|l|}{ Non-hydrogen atoms } \\
\hline Protein & 3110 & 3110 & 3109 & 3119 & 3164 & 3112 & 3135 & 3165 \\
\hline Water & 568 & 533 & 454 & 611 & 669 & 559 & 458 & 644 \\
\hline$R_{\text {factor }}(\%)^{\mathrm{b}}$ & 17.5 & 16.5 & 17.4 & 15.7 & 16.7 & 16.9 & 17.3 & 17.3 \\
\hline \multirow{2}{*}{\multicolumn{9}{|c|}{ r.m.s.d. from ideality }} \\
\hline & & & & & & & & \\
\hline Bond lengths $(\AA)$ & 0.005 & 0.010 & 0.005 & 0.019 & 0.007 & 0.004 & 0.007 & 0.007 \\
\hline Bond angles $\left({ }^{\circ}\right)$ & 0.858 & 1.336 & 0.882 & 1.85 & 1.060 & 0.833 & 1.100 & 1.048 \\
\hline Dihedrals $\left({ }^{\circ}\right)$ & 13.8 & 13.8 & 13.9 & 14.5 & 13.5 & 13.1 & 13.6 & 14.0 \\
\hline \multicolumn{9}{|l|}{ Ramachandran plot } \\
\hline Favoured regions (\%) & 98.7 & 98.7 & 98.4 & 98.4 & 98.7 & 98.4 & 98.7 & 98.2 \\
\hline Allowed regions (\%) & 1.3 & 1.3 & 1.6 & 1.6 & 1.3 & 1.6 & 1.3 & 1.8 \\
\hline \multicolumn{9}{|l|}{$B$-factors $\left(\AA^{2}\right)$} \\
\hline Average main chain & 11.2 & 14.2 & 15.2 & 11.4 & 13.3 & 12.4 & 17.1 & 15.0 \\
\hline Average side chain & 15.4 & 18.6 & 19.6 & 16.2 & 18.7 & 17.0 & 21.0 & 20.7 \\
\hline Average water & 27.4 & 29.8 & 28.4 & 29.2 & 31.1 & 27.4 & 30.0 & 33.6 \\
\hline
\end{tabular}

pocket, although the manner in which the Arg at $\mathrm{P} \Omega-2$ interacted with Asp114 differed. That is, in HLA-B`57:01-LTVQVARVW the $\mathrm{P} \Omega-2$ Arg formed a bi-dentate salt-bridge interaction with Asp114 (Fig. 4g), whilst in HLA-B 58 :01-LTVQVARVW the P $\Omega$ 2 Arg side chain was twisted by $60^{\circ}$ and the Asp 114 side chain rotated $90^{\circ}$ to accommodate the Val97Arg micropolymorphism (Fig. 4h). This altered the salt-bridge between the $\mathrm{P} \Omega-2 \mathrm{Arg}$ and Asp114 to a less favourable conformation in HLA-B*58:01, consistent with the reduced thermal stability of the complex (Fig. 4h, Table 1). In contrast, Arg and Lys were unable to be

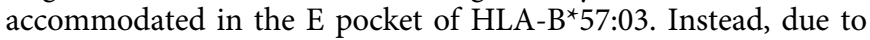
the reduced $\mathrm{E}$ pocket volume caused by the Ser116Tyr substitution, these residues deviated by $9.7 \AA$ and pointed out of the groove (Fig. $4 \mathrm{~d}-\mathrm{f}, \mathrm{i}$ ). The deviation at $\mathrm{P} \Omega-2$ was concomitant with a $5.3 \AA$ shift and $180^{\circ}$ rotation of the $\mathrm{P} \Omega-3$ residue to fill the C-pocket of HLA-B ${ }^{\star} 57: 03$ (Fig. $4 \mathrm{~d}-\mathrm{f}$ ). Overall, these structures showed that the buried polymorphisms generated minimal differences to the surface of the HLA molecule available to TCRs whilst engendering marked differences in the peptide surface landscape available for T-cell interaction.

Reciprocal T-cell alloreactivity occurs between allotypes. Vigorous T-cell alloresponses can be generated by a high degree of HLA class I mismatching between allogeneic individuals or as little as a single amino acid mismatch (e.g. across HLA-B44 allotypes $)^{28,35-37}$. Here we examined whether the closely related alleles HLA- ${ }^{\star}$ 57:01 and HLA- $B^{\star} 58: 01$ are capable of eliciting either anti-HLA-B ${ }^{\star} 58: 01 \quad\left(B^{\star} 57: 01\right.$ responder vs $B \star 58: 01$ stimulator) or anti-HLA- $B \star 57: 01(B \star 58: 01$ responder vs $\mathrm{B}^{\star}$ 57:01 stimulator) $\mathrm{CD}^{+}$T-cell alloreactivity, which would support distinct presentation of the immunopeptidome. Experiments did not include HLA-B ${ }^{\star 57: 03}$ due to a lack of availability of HLA-B ${ }^{\star} 57: 03^{+}$donors who are rare in Caucasian populations $s^{38,39}$. A total of 16 unidirectional mixed lymphocyte reactions (MLRs) were performed utilising a combinatorial matrix incorporating six healthy individuals (Fig. 5a, d,
Supplementary Table 3). Alloreactive $\mathrm{T}$ cells were expanded for 13 days, after which these bulk T-cell cultures were restimulated with a panel of B-lymphoblastoid cell lines (B-LCLs) expressing the mismatched stimulator HLA-A and -B alloantigens (Supplementary Table 3) to dissect their individual contribution (measured by interferon-gamma (IFN $\gamma$ ) production) to the overall alloresponse.

The first set of MLRs (1-4, 11, 12, 15 and 16; Fig. 5a, Supplementary Table 3) were designed to evaluate anti-HLA$B \star 58: 01$ T-cell alloreactivity between responders expressing HLAB57 (DHS011), HLA-B ${ }^{\star 57: 01 ~(D H S 006 ~ a n d ~ D H S 009) ~ o r ~ b o t h ~}$ HLA-B ${ }^{\star} 57: 01$ and HLA-B ${ }^{\star} 58: 01$ (heterozygote, AP012), and stimulators expressing HLA-B ${ }^{\star}$ 58:01 (AP013 and AP015). All HLA-A and -B mismatched alloantigens expressed by the stimulators, including HLA-B ${ }^{\star} 58: 01$, generated alloreactive CD8 ${ }^{+} \mathrm{T}$-cell responses. In contrast, no allo-specific $\mathrm{CD} 8^{+} \mathrm{T}$ cells were directed against HLA-B ${ }^{\star} 58: 01$ in the heterozygote responder (Fig. 5b, c). The second set of MLRs (5-10, 13 and 14; Fig. 5d, Supplementary Table 3) were designed to evaluate anti-HLA$B \star 57: 01$ T-cell alloreactivity between responders expressing HLA$B^{\star}$ 58:01 (AP013 and AP015), HLA-B`57:01 (matched, DHS006) or both HLA-B ${ }^{\star} 57: 01$ and HLA-B*58:01 (heterozygote, AP012) and stimulators expressing HLA-B57 (DHS011) or HLA-B ${ }^{\star 57: 01}$ (DHS009). Similar to the first set of MLRs, all HLA-A and -B mismatched alloantigens expressed by the stimulators generated alloreactive $\mathrm{CD}^{+}{ }^{+} \mathrm{T}$-cell responses, whilst no allo-specific $\mathrm{CD} 8^{+}$ $T$ cells were directed against HLA-B ${ }^{\star} 57: 01$ by either the HLA$B^{\star} 57: 01 / B^{\star} 58: 01$ heterozygote or the HLA-B ${ }^{\star} 57: 01$ matched responder (Fig. 5e, f). Thus, differences in self-peptide presentation by HLA-B ${ }^{\star} 57: 01$ and HLA-B ${ }^{\star} 58: 01$, not background proteome, generate alloreactivity between these related molecules.

\section{Discussion}

In order to resolve the impacts of micropolymorphism on the peptide repertoire, we comprehensively analysed data sets comprising 2673 HLA-B ${ }^{\star} 57: 01$-bound peptides, 3168 HLA-B ${ }^{\star}$ 57:03- 
a

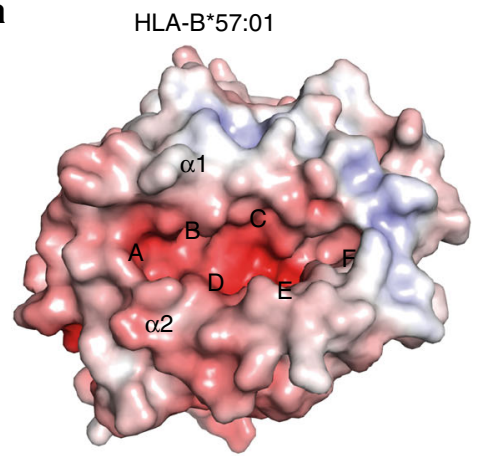

d

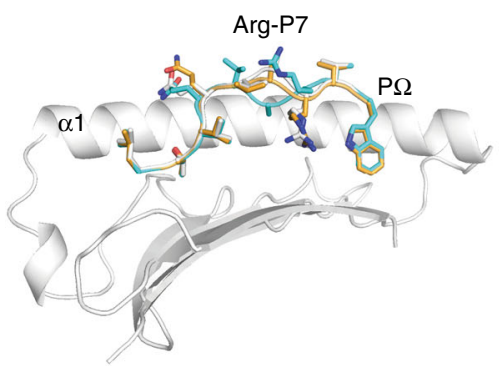

g

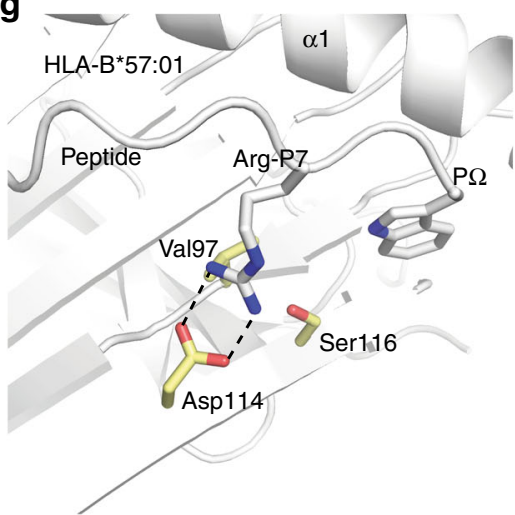

b

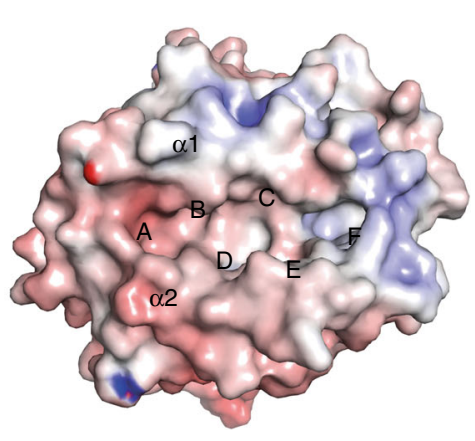

e

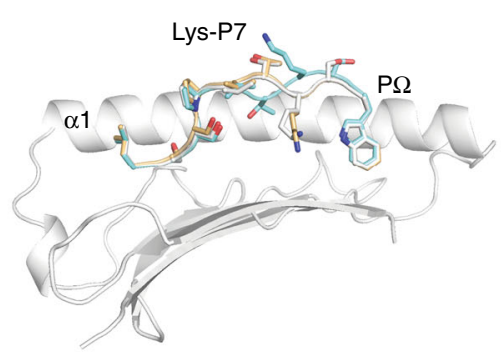

h

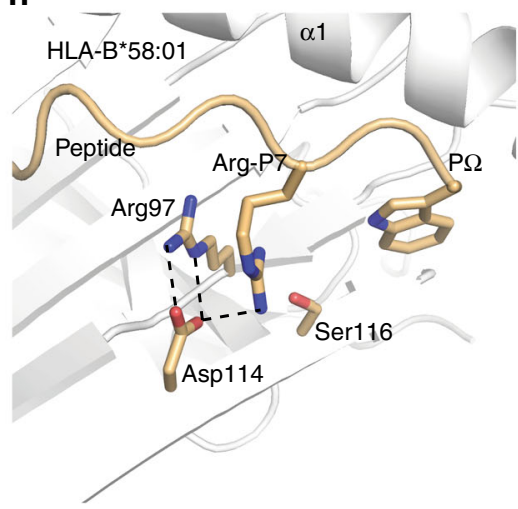

c

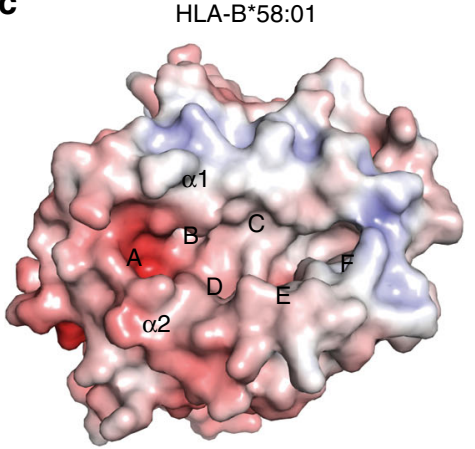

f

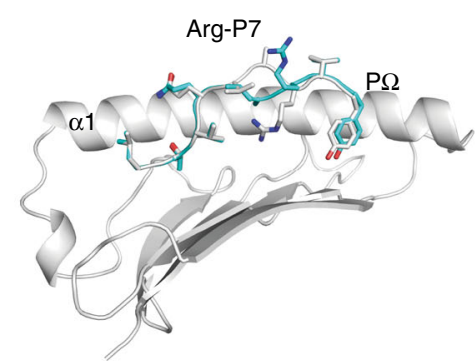

i

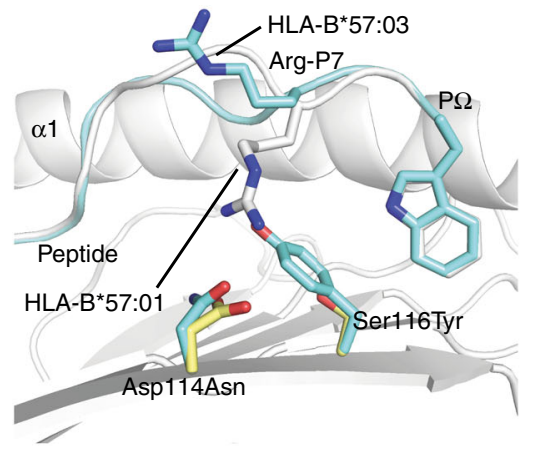

Fig. $4 \mathrm{HLA}-\mathrm{B}^{\star} 57: 01, \mathrm{HLA}-\mathrm{B}^{\star} 57: 03$ and $\mathrm{HLA}-\mathrm{B}^{\star} 58: 01$ present peptides in distinct conformations. a-c The electrostatic potential mapped to the surface of the structures of $H L A-B \star 57: 01, H L A-B \star 57: 03$ and HLA-B*58:01 respectively (red-electronegative, blue-electropositive). The $\alpha 1$ and $\alpha 2$ helices and the positions of peptide-binding pockets A-F are shown. d-f Superposition of the crystal structures of the LTVQVARVW, LSSPVTKSW and LTVQVARVY peptides (respectively) in complex with HLA-B`57:01 (grey), $B \star 57: 03$ (cyan) and $B^{\star} 58: 01$ (orange). The $\alpha 2$ helix has been removed for clarity. $\mathbf{g}$ The interaction between the P7Arg (from the peptide LTVQVARVW) and Asp114 in HLA-B`57:01. $\mathbf{h}$ The interaction between the P7Arg (from the peptide LTVQVARVW) and Asp114 in HLA-B*58:01. i Superposition of the LTVQVARVW peptides in complex with HLA-B*57:01 (grey) and $B^{\star} 57: 03$ (cyan). The presence of the Ser116Tyr micropolymorphism (HLA-B $57: 01->H L A-B^{\star} 57: 03$ ) prevents the binding of the P7Arg in the E pocket of HLA-B $57: 03$

bound peptides and 2526 HLA-B ${ }^{\star} 58: 01$-bound peptides isolated from monoallelic C1R transfectants ${ }^{15}$. Due to differences in the ionisation efficiencies of individual peptides, which precludes absolute peptide quantitation without the introduction of sequence-matched isotope-labelled standards, distribution of specific sequence features across the population of peptides was used to define and compare the peptide-binding motif of each allotype. The analysis was performed at three levels; first, at the level of amino acid preference individually for 9, 10 or $11 \mathrm{mer}$ peptide ligands; second, at the level of amino acid physical chemistry using a recently established PCA-based statistical analysis of the data; and finally, at the level of proteome enrichment. The majority of peptide ligands identified were 9-11 residues in length and possessed Ser, Thr or Ala at P2, and aromatic residues at their $C$ terminus, consistent with investigations of HLA-B ${ }^{\star 57: 01}$ and HLA-B ${ }^{\star 58: 01}$ from other groups ${ }^{26,40,41}$. Of the three allotypes, the previously underexplored HLA-B ${ }^{\star 57: 03 ~ h a d ~}$ the most distinctive binding preferences. Although length and P2 preferences were equivalent to the other allomorphs, preferences at $\mathrm{P} \Omega$ differed, showing greater enrichment of Phe and greater sampling of ligands with smaller $\mathrm{P} \Omega$ residues. Despite this, HLA-

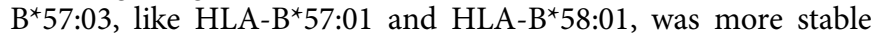
when in complex with peptides containing the bulky $P \Omega \operatorname{Trp}$ (compared to P $\Omega$ Tyr or Phe). The incongruity between the stabilisation effects conferred by Trp vs Phe at P9 and their prevalence in the repertoire of HLA-B ${ }^{\star} 57: 03$ suggests an interplay between ligand availability (Trp and Phe constitute approximately 1 and $4 \%$ of the human proteome respectively) and complex stability in shaping the resultant peptide repertoire, which may be further influenced by interactions with the peptide-loading complex. Indeed, evidence of a hierarchy of tapasin dependence between these allomorphs (HLA-B ${ }^{\star}$ 57:01 > HLA-B ${ }^{\star}$ 58:01 > HLA- 
a

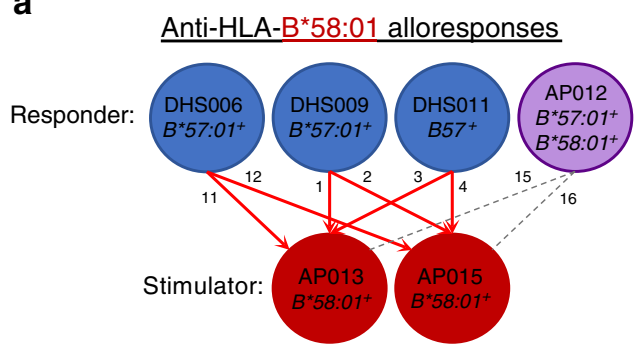

$\longrightarrow$ Anti-HLA-B*58:01 alloresponse observed No anti-HLA-B*58:01 alloresponse observed

d

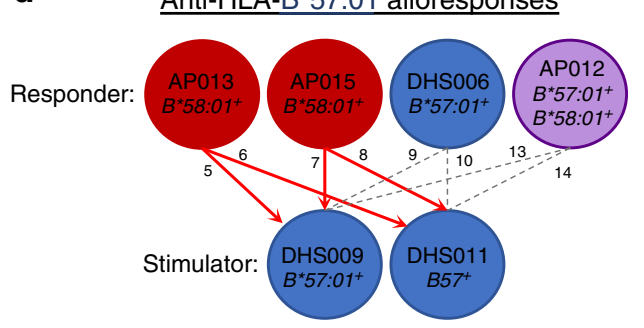

$\longrightarrow$ Anti-HLA-B*57:01 alloresponse observed No anti-HLA-B*57:01 alloresponse observed b

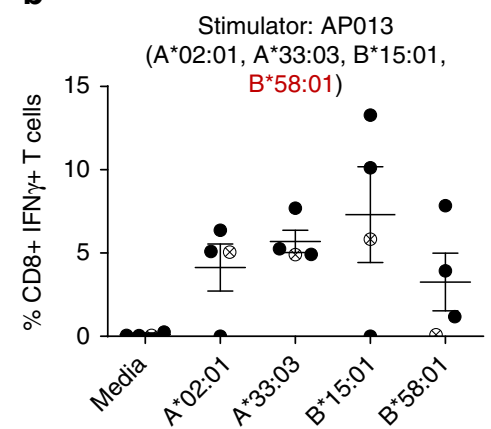

c

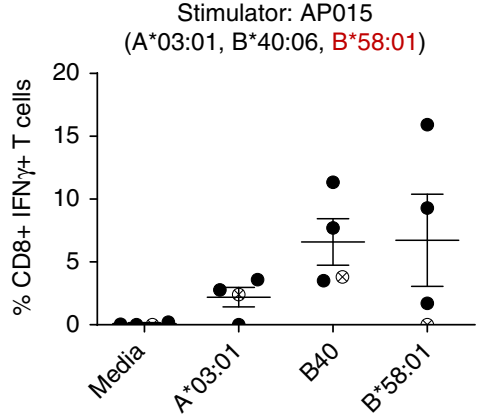

HLA molecule of secondary stimulator

e

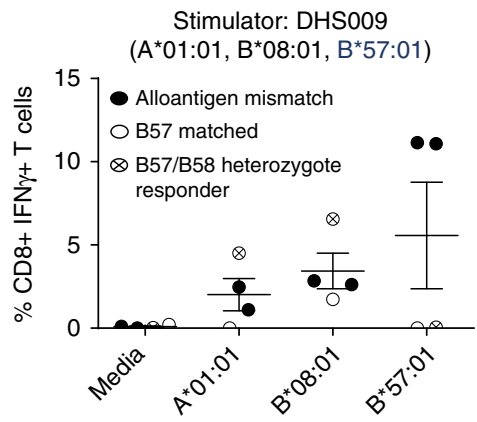

f

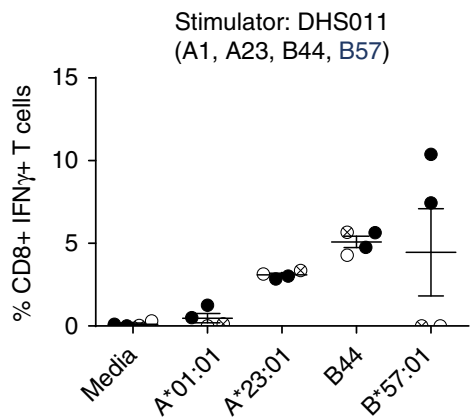

HLA molecule of secondary stimulator

Fig. 5 Reciprocal T-cell alloreactivity is observed between HLA-B*57:01 and HLA-B*58:01. Allogeneic MLRs were performed to measure the alloresponse to either HLA-B $57: 01$ or HLA-B 58:01 in healthy donors. Schematics show the responder/stimulator combinations utilised to stimulate outgrowth of antiHLA-B ${ }^{\star}$ 58:01 (a) and anti-HLA-B*57:01 (d) allo-specific T cells. Numbers correspond to the full details of each responder/stimulator combination provided in Supplementary Table 3. b, c, e, $\mathbf{f} I \mathrm{FN} \gamma$ responses by $\mathrm{CD} 8^{+} \mathrm{T}$ cells of outgrown responders in a secondary stimulation utilising APCs expressing single HLA molecules of the primary stimulator as noted. Mean IFN $\gamma$ response $( \pm$ SEM) by all responders is shown for each HLA (calculated as IFN $\gamma$ response minus background as indicated in Supplementary Table 3). Anti-HLA-B $58: 01$ alloreactivity was generated following stimulation with either AP013 (b) or AP015 (c) for allogenic mismatched responders (solid circles) but not for the HLA-B ${ }^{\star 57: 01 / B}$ 58:01 heterozygote responder (crossed circle). Anti-HLA$B \star 57: 01$ alloreactivity was generated following stimulation with either DHS009 (e) or DHS011 (f) for allogenic mismatched responders (solid circles). Anti-

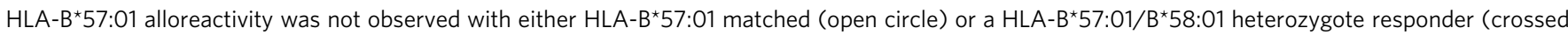
circle). Note that absent responses to HLA-A*02:01 in $\mathbf{b}$ correspond to MLR 11, where responders/stimulators were matched for HLA- $A^{\star} 02: 01$

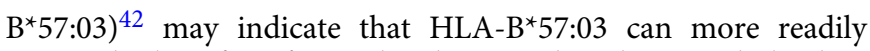
escape the benefits of peptide editing within the peptide-loading complex, as suggested for other alleles ${ }^{43}$.

We further defined a secondary anchor site that modulated peptide affinity for the HLA molecule and distinguished the HLA-B ${ }^{\star 57: 01}$ peptide-binding motif. Arg appeared at P7 of 9mers (and $P \Omega-2$ of longer peptides) almost exclusively in the HLA-B ${ }^{\star} 57: 01$ data set and correlated with stabilisation of HLA$\mathrm{B}^{\star} 57: 01$ complexes by $\mathrm{P} \Omega-2$ Arg. In contrast, $\mathrm{P} \Omega-2$ Arg negatively impacted the stability of HLA-B ${ }^{\star 57: 03}$ and HLA-B ${ }^{\star} 58: 01$ complexes. Structural analysis of bound peptide conformation showed a pronounced change in orientation of $\mathrm{P} \Omega-2 \mathrm{Arg} / \mathrm{Lys}$ conferred by the Ser116Tyr polymorphism of HLA-B ${ }^{\star} 57: 03$ that would markedly change the surface presented to $\mathrm{T}$ cells. More subtle changes were induced by the Val97Arg polymorphism in HLA$B \star 58: 01$. These observations strongly parallel differences in peptide presentation between micropolymorphic allotypes HLA$B^{\star} 35: 01$ and HLA $-B^{\star} 35: 08$, in which a Leu156Arg substitution generates a secondary anchor site that improves the binding kinetics of peptides containing a negatively charged residue at P5. Of note, this results in distinct immunodominance hierarchies for human cytomegalovirus pp65 T-cell epitopes in HLA-B ${ }^{\star} 35: 01^{+}$ and HLA-B ${ }^{\star} 35: 08^{+}$individuals ${ }^{18}$. In addition, the Leu156Arg polymorphism can alter peptide conformation and the plasticity of bound ligands, resulting in divergent $\mathrm{T}$-cell responses to several
Epstein Barr virus epitopes. Changes in T-cell responses were attributed to the adoption of different conformations within the antigen-binding cleft and/or the ability of the HLA-peptide complex to accommodate conformational change on TCR engagement ${ }^{17,44,45}$. Although HLA-B ${ }^{\star} 57: 01$, HLA-B ${ }^{\star} 57: 03$ and HLA-B ${ }^{\star} 58: 01$ all associate with long-term non-progression of HIV-1 infection to acquired immunodeficiency syndrome ${ }^{21,22}$, differences in viral load between patients possessing different HLA-B57/58 alleles correlate with differential immunogenicity of identical peptide ligands ${ }^{23}$. The differences in peptide presentation described here provide grounds for this differential T-cell recognition of B57/B58-bound ligands. Indeed, HLA-B ${ }^{\star} 57: 01$ and HLA-B ${ }^{\star} 57: 03$ restricted presentation of the 11mer KAFSPEVIPMF HIV-Gag162-172 epitope induce distinct T-cell respon$\mathrm{ses}^{24}$. Although presented in similar conformations by both molecules, Tyr116 of HLA-B ${ }^{\star} 57: 03$ reduces the space available to accommodate changes in KAFSPEVIPMF conformation on TCR ligation, requiring re-orientation of Tyr116, and impacting TCR selection through altered TCR-pHLA affinity ${ }^{25}$. In contrast, our structural analyses encompass peptides of optimal length to be contained within the antigen-binding cleft (9mers). These peptides occupy the cleft without marked bulging or overhang $^{25,45-48}$, however polymorphic residues of the cleft cause distinct amino acid residue orientations. Our data suggest that 910mer HLA-B57/58 HIV-1 epitopes possessing Arg or Lys at P $\Omega$ - 
2 such as QATQDVKNW (Gag308-316), and its escape variants, and AVRHFPRIW (Vpr30-38) 11,23 may adopt distinct conformations across the B57 family and generate structurally distinct targets for T-cell responses, which, in conjunction with quantitative differences in contribution to the immunopeptidome, may in turn explain the clinical differences in patients with these allotypes.

The observed alloreactivity between HLA-B ${ }^{\star} 57: 01$ and HLA$\mathrm{B}^{\star} 58: 01$ further indicates that the differences in presentation of the self-proteome described are sufficient to alter recognition reminiscent of alloresponses between HLA-B ${ }^{\star} 44: 02$ and HLA$\mathrm{B}^{\star} 44: 03$ molecules, which differ by a single residue buried within the antigen-binding cleft (Asp156Leu) and induce alloreactivity when mismatched in transplant scenarios ${ }^{49,50}$. Although the residue 156 polymorphism does not impact the primary anchor pockets of these allotypes, resulting in highly similar peptidebinding motifs and immunopeptidomes, differences are sufficient to stimulate alloresponses and are augmented by the ability of these allotypes to present identical peptides in structurally distinct conformations ${ }^{28}$. Thus, caution may be necessary when embarking on transplants between individuals bearing HLA-B57/ 58 mismatches.

In summary, we present the first comprehensive investigation of the impact of micropolymorphism on the immunopeptidome of HLA class I molecules. This has involved detailed analysis of ligand-binding specificity, qualitative and quantitative analysis of the immunopeptidomes of three clinically important HLA-B57 family members, and structural and functional characterisation of these differences. We show that micropolymorphism influences the immunopeptidome at several interlinked levels: (i) the repertoire of displayed peptides; (ii) quantity of displayed peptides; (iii) stability of pHLA, which will impact on the dynamics of the immunopeptidome; and (iv) conformation of pHLA. Importantly, such differences may amplify the responding T-cell repertoire against pathogens in heterozygous individuals but restrict transplantation options when considering micropolymorphic mismatches between donor-recipient pairings. Moreover, these findings suggest a need to look beyond qualitative analysis of the peptide repertoire when trying to unravel the nature of HLA-peptide presentation that dictates susceptibility to viral infection, autoimmunity, transplant rejection and drug hypersensitivity.

\section{Methods}

Ethics. Healthy individuals $(n=6)$ expressing either HLA-B ${ }^{\star}$ 57:01, HLA-B ${ }^{\star}$ 58:01 or both were recruited for the study. Ethics was granted from both Monash University (DHS numbers) and the Australian Bone Marrow Donor Registry (AP numbers) human ethics committees. Informed consent was obtained from all participants and research was performed in compliance with ethical regulations for the use of human samples.

Peripheral blood mononuclear cell isolation. Peripheral blood samples were collected in heparinised vacutainer tubes and peripheral blood mononuclear cells (PBMCs) were isolated by Ficoll-Paque (GE Healthcare, Sweden) and density gradient centrifugation and cryopreserved until required.

Cell lines and culture. C1R.B ${ }^{\star} 57: 01, C 1 R . B^{\star} 57: 03$ and C1R.B ${ }^{\star 58: 01}$ are B-LCLs, derived from the $\mathrm{C} 1 \mathrm{R}$ cell line that expresses reduced amounts of HLA class I (reduced HLA-A2, reduced HLA-B35 and normal HLA-Cw4 ${ }^{51,52}$ ), and transfected with HLA-B ${ }^{\star} 57: 01$, HLA-B ${ }^{\star} 57: 03$ or HLA-B ${ }^{\star 58: 01}$ cDNA cloned into the pcDNA3.1(-) vector (Invitrogen, USA) ${ }^{15}$.

T-cell alloreactivity assays included the following B-LCLs $\left(9053^{53}: A^{*} 33: 03\right.$, $B^{\star} 44: 03$ and $C^{\star} 14: 03$; T241: $A^{\star} 23: 01, B^{\star} 07: 02, B^{\star} 41: 01, C^{\star} 07: 02$ and $C^{\star} 08: 02 ; A 21$ : $\mathrm{A} 2$ and $\mathrm{B} 40$ ) and transfected cell lines (C1R.parental/ $\mathrm{A}^{\star} 01: 01 / \mathrm{A}^{\star} 02: 01 / \mathrm{A}^{\star} 03: 01 /$ $\left.\mathrm{B}^{\star} 07: 02 / \mathrm{B}^{\star} 08: 01 / \mathrm{B}^{\star} 15: 01 / \mathrm{B}^{\star} 44: 02 / \mathrm{B}^{\star} 44: 03 / \mathrm{B}^{\star} 57: 01 / \mathrm{B}^{\star} 58: 01\right)$. C1R transfectants were produced within the McCluskey laboratory (Peter Doherty Institute, University of Melbourne, Victoria); T241 and A21 were provided by the Victorian Transplantation and Immunogenetics Service (West Melbourne, Victoria).

All cell lines were cultured in RF10 [RPMI 1640 (Life Technologies, USA) supplemented with $10 \%$ foetal calf serum (Sigma, St Louis, USA), 7.5 mM HEPES
(MP Biomedicals, Germany), $100 \mathrm{U} \mathrm{mL}^{-1}$ Pen-Strep (benzyl-penicillin/ streptomycin, Life Technologies, USA), $2 \mathrm{mM}$ L-glutamine (MP Biomedicals, Germany), $76 \mu \mathrm{M} \beta$-mercaptoethanolamine (Sigma-Aldrich, USA) and $150 \mu \mathrm{M}$ non-essential amino acids (Life Technologies, USA)] at $37^{\circ} \mathrm{C}, 5 \% \mathrm{CO}_{2}$. Maintenance of transfected HLA expression during long-term culture was facilitated by addition of Geneticin, $0.4-0.5 \mathrm{mg} \mathrm{mL}^{-1}$ (G418; Life Technologies, USA), or Hygromycin B, $0.2-0.3 \mathrm{mg} \mathrm{mL}^{-1}$ (Life Technologies, USA). Increased HLA class I expression (as compared to C1R parental) was confirmed via flow cytometry after staining with the HLA class I pan-specific monoclonal antibody $\mathrm{W} 6 / 32^{54}$ (produced in house from the W6/32 hybridoma) and Goat $\mathrm{F}\left(\mathrm{ab}^{\prime}\right) 2$ AntiMouse $\operatorname{IgG}(\mathrm{H}+\mathrm{L})$, Human ads-PE (1:500, catalogue number 1032-09, Southern Biotech, USA). All cell lines were tested for mycoplasma contamination.

Motif characterisation and data set comparisons. We had previously isolated and sequenced peptide ligands from HLA class I of $10^{9} \mathrm{C} 1 \mathrm{R}-\mathrm{B}^{\star} 57: 01, \mathrm{C} 1 \mathrm{R}-\mathrm{B}^{\star} 57: 03$ and C1R-B ${ }^{\star} 58: 01$ cells by LC-MS/MS using an information-dependent acquisition (IDA) strategy ${ }^{15}$. Spectra were assigned with ProteinPilot ${ }^{\mathrm{TM}}$ software version 5.0 (SCIEX, USA) searching against the reviewed Swiss-Prot human proteome (accessed November 2017) and peptide identities determined subject to strict bioinformatic criteria, assigning confidence values to each peptide and including the use of a decoy database to calculate the FDR. Peptides known to bind the endogenous HLA class I of C1R cells (HLA-C*04:01 and HLA-B*35:03) ${ }^{55}$ were removed before subsequent analysis. A further list of peptide contaminants, generated by comparison of a large number of similar elution experiments for MHC and MHCII were also disregarded, in addition to peptides of the HLA proteins (Supplementary Data 3). To characterise the peptide-binding motif of each HLA allotype, distinct peptides identified within three biological replicate experiments were filtered using a confidence cut-off for a 5\% local FDR (95.2-97) and pooled to generate a single data set for analysis. The frequency of peptides (non-redundant by sequence) of specific lengths and/or possessing a particular amino acid at a specified position within the peptide was then calculated and sequence motifs generated for 9-11 residue peptides. Heat maps of the inter-position coupling matrices were generated for each of the 9 mer, 10 mer and 11 mer peptides. Statistical coupling of two sites in the peptide was defined as the degree to which amino acid frequencies at one site change in response to a perturbation of frequencies at a second site ${ }^{56}$. Coupling matrices were processed and analysed with custom Perl and MATLAB (The MathWorks Inc., Natick, MA) scripts ${ }^{57}$. Scripts are available (https://github.com/jlmendozabio/covariation_stats).

For PCA based on amino acid physicochemical properties, 4 quantitative biophysical properties (molecular weight, hydropathy index, surface area and isoelectric point) were determined for each position of the peptide. We also incorporated 20 additional parameters at each amino acid position describing the identity of the amino acid present. From the points generated by the PCA, a twodimensional kernel density plot was used to more clearly display large numbers of peptides. These variables were processed for peptides of 9-11 amino acids in length from each HLA allotype. For each different combination of PC scores, we performed clustering by $k$-means clustering. Silhouette analysis was used to provide a quantitative assessment of cluster similarity. On the basis of peaks in silhouette coefficient across the number of clusters, peptides were assigned into one of the two distinctive clusters present in all allotypes and for all peptide lengths by using $k$ means clustering $(k=2)$ on the first two principal components. To visualise the sequence motifs present in each cluster, peptide sequences were extracted from each cluster and their motifs generated based on residue frequency as described above. These analyses were performed using a custom $\mathrm{R}$ script ${ }^{58-61}$ (available at https://github.com/ParhamLab/PeptidePCA/tree/master/R).

Amino acid enrichment/regulation over prevalence in the human proteome was determined using the icelogo v1.2 stand-alone software via the static reference method (reference Homo sapiens Swiss-Prot means), and is depicted as FC (FC= prevalence in data set/prevalence in human proteome) for enriched amino acids, and converted $\mathrm{FC}\left(\mathrm{FC}_{\mathrm{con}}=-1 / \mathrm{FC}\right)$ for negatively regulated residues ${ }^{31}$. FC or $\mathrm{FC}_{\text {con }}$ was only depicted where the $Z$-score fell outside the confidence interval for a $p$-value of 0.05 . Post-translational modifications of peptides were not considered during motif analysis.

To perform sequence-based comparison of data sets for overlap within the peptide repertoire, all peptides in a data set identified with a confidence $\geq 95$ were included. Peptides identified with a confidence $>20$ were also included if, and only if, they appeared in a compared data set with a confidence $\geq 95$. Modifications were considered in overlap analysis.

Purification of HLA-peptide complexes. C1R transfectants were grown to high density in $100 \mathrm{~mL}$ RF10 containing $0.5 \mathrm{mg} \mathrm{mL}^{-1} \mathrm{G} 418$ in T175 tissue culture flasks (Greiner Bio-One International AG, Austria). Cells were harvested in batches of $10^{8}$ cells by centrifugation $\left(1200 \times g, 20 \mathrm{~min}, 4^{\circ} \mathrm{C}\right)$, washed twice in chilled phosphate-buffered saline and frozen on dry ice for $15 \mathrm{~min}$ or by submersion in liquid nitrogen. Pelleted cells were stored at $-80^{\circ} \mathrm{C}$ until time of use. Detergentbased lysis was performed by resuspending cell pellets in $5 \mathrm{~mL}$ lysis buffer [0.5\% IGEPAL (Sigma-Aldrich, USA), $50 \mathrm{mM}$ Tris, pH 8, $150 \mathrm{mM} \mathrm{NaCl}$ (Merck-Millipore, Germany) and protease inhibitors (Complete Protease Inhibitor Cocktail Tablet [1 tablet per $50 \mathrm{~mL}$ solution]; Roche Molecular Biochemicals, Switzerland)] 
and incubating for $45 \mathrm{~min}$ at $4{ }^{\circ} \mathrm{C}$ with slow end-over-end mixing. Lysates were cleared by centrifugation at $16000 \times g$ for $20 \mathrm{~min}$ at $4^{\circ} \mathrm{C}$.

HLA-peptide complexes were immunoaffinity purified from cell lysates using 1 mg W6/32 monoclonal antibody crosslinked to protein A sepharose ${ }^{6}$. Bound complexes were eluted with $2 \mathrm{~mL} 10 \%$ acetic acid. The eluted mixture of peptides, class I heavy chain and $\beta_{2}$-microglobulin $\left(\beta_{2} \mathrm{~m}\right)$ was fractionated on a $4.6 \mathrm{~mm}$ internal diameter $\times 50 \mathrm{~mm}$ long monolithic reversed-phase (RP) $\mathrm{C}_{18}$ highperformance liquid chromatography (HPLC) column (Chromolith Speed Rod, Merck-Millipore, Germany) utilising an ÄKTAmicro ${ }^{\text {Tx }}$ HPLC system (GE Healthcare, UK; Unicorn v5.11 software) and using a mobile phase consisting of buffer A (0.1\% trifluoroacetic acid (TFA) [Thermo Scientific, USA]) and buffer B ( $80 \%$ acetonitrile (ACN) [Fisher Scientific, USA] and $0.1 \%$ TFA), running at $1 \mathrm{~mL}$ $\min ^{-1}$ with a gradient of B of $2-40 \%$ over $4 \mathrm{~min}, 40-45 \%$ over $4 \mathrm{~min}$ and $45-99 \%$ over $2 \mathrm{~min}$, collecting $500 \mu \mathrm{L}$ fractions. Three fraction pools were generated and vacuum concentrated for MS analysis. Ultraviolet absorbance of eluted material was monitored at $215 \mathrm{~nm}$. The relative amount of HLA purified was measured as the area under the curve for the $\beta_{2} \mathrm{~m}$.

MRM quantification of HLA-bound peptides. Fraction pools from the RP-HPLC purification were concentrated using a speed vacuum concentration system (LABCONCO, USA). MRM detection was performed using an AB SCIEX QTRAP 5500 mass spectrometer, equipped with a Tempo nanoLC (Eksigent) autosampler and cHiPLC nanoflex (Eksigent) and utilising Analyst 1.6 (SCIEX) software. Samples were injected and loaded onto a trap column $(200 \mu \mathrm{m} \times 0.5 \mathrm{~mm}$ ChromXP $\mathrm{C}_{18}$-CL packed with $3 \mu \mathrm{m}$ particles, nominal pore size $120 \AA$ ) at a flow rate of $5 \mu \mathrm{L}$ $\mathrm{min}^{-1}$ in $98 \%$ buffer A (0.1\% formic acid in water), $2 \%$ buffer B (95\% ACN and $0.1 \%$ formic acid in water) for $10 \mathrm{~min}$. Samples were eluted from the trap column and over a cHiPLC column $\left(75 \mu \mathrm{m} \times 15 \mathrm{~cm}\right.$ ChromXP $\mathrm{C}_{18^{-}}$packed with $3 \mu \mathrm{m}$ particles, nominal pore size $120 \AA$ ) at $300 \mathrm{~nL} \mathrm{~min}^{-1}$ using the following gradient conditions: $0-3 \min 2-10 \% \mathrm{~B}, 3-62 \mathrm{~min} 10-50 \% \mathrm{~B}, 62-65 \min 40-80 \% \mathrm{~B}, 65-70$ min hold at $80 \% \mathrm{~B}, 70-73$ min $80-2 \%$ B, followed by equilibration at $2 \%$ B for 7 min. The QTRAP 5500 was operated in MRM mode in unit resolution for Q1 and Q3, coupled to an IDA criterion set to trigger an EPI scan (10 $000 \mathrm{Da} \mathrm{s}^{-1}$; rolling CE; unit resolution) following any MRM transition exceeding 600 counts. Triggering MRM transitions were ignored for the subsequent $6 \mathrm{~s}$.

The detection of all three to four transitions overlapping at a particular retention time, accompanied by MRM triggered-MS/MS fragmentation in at least one experiment, was used as an indicator of peptide presence. Fragment ion intensity rankings were compared to those in initial IDA-based discovery experiments using a spectral library generated from data for the three HLA allotypes using Skyline 64 bit 3.5.0.9319 (MacCoss Laboratory ${ }^{62}$ ) and calculated as a dot product value. Peptides detected in a sample without MS/MS validation were considered valid if the retention time (RT) was $\pm 1.5 \mathrm{~min}$ of the average RT for MS/MS validated appearances of that peptide and the dot product value was $>0.7$. Relative peptide abundance was calculated as the total area under the curve for the detected transitions using Skyline software, normalised to the amount of purified HLA from which the sample was derived, allowing comparison between samples in the absence of absolute quantitation.

Allogeneic T-cell stimulation. T-cell cultures were generated from $5 \times 10^{6}$ responder PBMCs stimulated with $2.5 \times 10^{6}$ irradiated allogeneic PBMCs. Culture medium was supplemented with $20 \mathrm{U} \mathrm{mL}^{-1}$ recombinant human IL-2 (Cetus) and changed every 2-3 days to maintain saturating levels of nutrients and growth factors. On day $13,2 \times 10^{5}$ responders from the T-cell culture were restimulated with $10^{5}$ B-LCLs expressing allo-HLA. After $2 \mathrm{~h}$ of coincubation $\left(37^{\circ} \mathrm{C}, 5 \% \mathrm{CO}_{2}\right), 10 \mu \mathrm{g} \mathrm{mL}^{-1}$ Brefeldin A (Sigma-Aldrich, USA) was added for a further $4 \mathrm{~h}$. Responder $\mathrm{CD}^{+} \mathrm{T}$ cells were stained with anti-CD8 PerCP-Cy5.5 (1:20, clone SK1, catalogue number 341051, Becton Dickinson [BD] Biosciences, USA), anti-CD4 PE (1:20, clone RPA-T4, catalogue number 555347, BD Biosciences) and a viability dye (1:750, LIVE/DEAD ${ }^{\text {six }}$ Fixable Aqua Dead Cell Stain, $405 \mathrm{~nm}$ excitation, catalogue number L34957, Thermo Fisher), fixed with $1 \%$ paraformaldehyde (ProSciTech, Australia) and permeabilised with 0.3\% Saponin (Sigma-Aldrich, USA) containing anti-IFN $\gamma$ PE-Cy7 (1:250, clone B27, catalogue number 557643, BD Biosciences, USA) and acquired on a LSRII flow cytometer (BD, USA) utilising BD FACSDIVA ${ }^{\mathrm{m}}$ software. The percentage of allo-specific $\mathrm{CD}^{+} \mathrm{T}$ cells producing IFN $\gamma$ was analysed using FlowJo software (Tree Star Inc., USA ${ }^{36}$, utilising the gating strategy shown in Supplementary Fig. 10. Sample numbers were dictated by availability of HLA-B ${ }^{\star} 57: 01 /$ HLA-B ${ }^{\star} 58: 01$ PBMC.

Recombinant HLA-peptide complex generation. The HLA- $B{ }^{*}$ 77:01, $H L A$ $B^{\star} 57: 03, H L A-B^{\star} 58: 01$ and $\beta_{2} m$ genes were sub-cloned into the pET-30 expression vector and were expressed into inclusion bodies separately in Escherichia coli. The HLA complexes were refolded in the presence of the peptides listed in Table 1 and purified as described previously ${ }^{63}$. Briefly, $90 \mathrm{mg}$ HLA heavy chain was refolded by rapid dilution in a solution containing $3 \mathrm{M}$ urea (Sigma-Aldrich, USA), $100 \mathrm{mM}$ Tris-HCl, pH 8.0 (Sigma-Aldrich, USA), $400 \mathrm{mM}$ L-arginine-HCl, $5 \mathrm{mM}$ reduced glutathione (Sigma-Aldrich, USA) and $0.5 \mathrm{mM}$ oxidised glutathione (SigmaAldrich, USA) in the presence of $30 \mathrm{mg} \beta_{2} \mathrm{~m}$ and $10 \mathrm{mg}$ of the appropriate peptide for $48 \mathrm{~h}$. The refolded HLA-peptide complexes were dialysed into $10 \mathrm{mM}$ Tris, $\mathrm{pH}$ 8.0, and purified by size-exclusion chromatography using HiLoad 16/60 Superdex $200 \mathrm{pg}$ (GE Healthcare, USA) columns on an AKTA Purifier (GE Healthcare, USA) FPLC chromatography systems in $10 \mathrm{mM}$ Tris, $\mathrm{pH} 8.0$, and $150 \mathrm{mM} \mathrm{NaCl}$ buffer. Final purification was by anion exchange using a HiTrap Q Fast Flow column (GE Healthcare, USA) on the same AKTA system in $10 \mathrm{mM}$ Tris $\mathrm{pH} 8.0$ buffer with a $\mathrm{NaCl}$ gradient from 0 to $500 \mathrm{mM}$ over $45 \mathrm{~min}$.

Thermal melt experiments. Thermal stability assays were performed at 0.5 and 1 $\mathrm{mg} \mathrm{mL} \mathrm{m}^{-1}$ HLA-peptide complex in $10 \mathrm{mM}$ Tris and $150 \mathrm{mM} \mathrm{NaCl}, \mathrm{pH} 8.0$ in a reaction volume of $25 \mu \mathrm{L}$ in duplicate except where otherwise indicated. Protein unfolding was monitored by the addition of the fluorescent dye SYPRO ${ }^{\circ}$ Orange (Sigma-Aldrich, USA) at $10 \times$ concentration. Refolded complexes were heated from 35 to $90{ }^{\circ} \mathrm{C}$ at a heating rate of $1{ }^{\circ} \mathrm{C} \mathrm{min}^{-1}$ in the Real Time Detection system (Rotor-Gene ${ }^{\star} \mathrm{Q}, \mathrm{QIAGEN}$ ) and fluorescence intensity was measured using an excitation wavelength of $530 \mathrm{~nm}$ and emission at $555 \mathrm{~nm}$.

X-ray crystallography. The peptide sequences crystallised in complex with HLA$B^{\star} 57: 01$, HLA-B ${ }^{\star} 57: 03$ and HLA-B ${ }^{\star} 58: 01$ are noted in Table 1. HLA-peptide complexes were concentrated to $\sim 10 \mathrm{mg} \mathrm{mL}^{-1}$ and crystallised at $294 \mathrm{~K}$ by the hanging-drop vapour-diffusion method from a solution comprising $12-20 \%$ PEG 4000, 0.2 M ammonium acetate and $0.1 \mathrm{M}$ tri-sodium citrate $\mathrm{pH}$ 5.4-5.6. Prior to data collection, crystals were equilibrated in reservoir solution with $10 \%$ glycerol added as a cryoprotectant and then flash-cooled in a stream of liquid nitrogen at $100 \mathrm{~K}$. Data sets were collected at the MX2 beamline (Australian Synchrotron, Victoria). The data were recorded on a Quantum-315 CCD detector and were integrated and scaled using MOSFLM and SCALA from the CCP4 programme suite ${ }^{64-66}$. Details of the data processing statistics are summarised in Table 2. Phases for the structures were determined by molecular replacement as implemented in PHASER ${ }^{67}$ with HLA-B ${ }^{\star} 57: 01-$ LF9 used as the search model (Protein Data Bank accession number: $2 \mathrm{RFX}^{34}$ ). Refinement of the models proceeded with iterative rounds of manual building in COOT $^{68}$, refinement in PHENIX ${ }^{69}$ and validation with MOLPROBITY ${ }^{69}$. Refinement statistics are summarised in Table 2.

Code availability. Scripts for co-variation analysis and PCA are available at https:// github.com/jlmendozabio/covariation_stats and https://github.com/ParhamLab/ PeptidePCA/tree/master/R.

\section{Data availability}

Proteomics data sets analysed during this study have been deposited to the ProteomeXchange Consortium via the PRIDE ${ }^{70}$ partner repository with the data set identifiers PXD008570 (C1R.B*57:01 LC-MS/MS), PXD008571 (C1R.B*57:03 LCMS/MS), PXD008572 (C1R-B`58:01 LC-MS/MS) and PXD009850 (LC-MRM). Coordinates and structure factors were deposited in the PDB with the following codes: B5701-LSSPVTKSW 5VUD; B5701-LTVQVARVW 5VUE; B5701LTVQVARVY 5VUF; B5703-LSSPVTKSW 5VVP; B5703-LTVQVARVW 5VWD; B5703-LTVQVARVY 5VWF; B5801-LSSPVTKSW 5VWH; and B5801LTVQVARVW 5VWJ. All other data are available from the corresponding author on reasonable request.

Received: 8 August 2017 Accepted: 12 October 2018

Published online: 08 November 2018

\section{References}

1. Robinson, J. et al. The IPD and IMGT/HLA database: allele variant databases. Nucleic Acids Res. 43, D423-D431 (2015).

2. Reche, P. A. \& Reinherz, E. L. Sequence variability analysis of human class I and class II MHC molecules: functional and structural correlates of amino acid polymorphisms. J. Mol. Biol. 331, 623-641 (2003).

3. Adams, E. J. \& Luoma, A. M. The adaptable major histocompatibility complex (MHC) fold: structure and function of nonclassical and MHC class I-like molecules. Annu. Rev. Immunol. 31, 529-561 (2013).

4. Madden, D. R. The three-dimensional structure of peptide-MHC complexes. Annu. Rev. Immunol. 13, 587-622 (1995).

5. Williams, A. P., Peh, C. A., Purcell, A. W., McCluskey, J. \& Elliott, T. Optimization of the MHC class I peptide cargo is dependent on tapasin. Immunity 16, 509-520 (2002).

6. Purcell, A. W. et al. Quantitative and qualitative influences of tapasin on the class I peptide repertoire. J. Immunol. 166, 1016-1027 (2001).

7. Bowness, P. HLA-B27. Annu. Rev. Immunol. 33, 29-48 (2015).

8. Schittenhelm, R. B., Sian, T. C., Wilmann, P. G., Dudek, N. L. \& Purcell, A. W. Revisiting the arthritogenic peptide theory: quantitative not qualitative changes in the peptide repertoire of HLA-B27 allotypes. Arthritis Rheumatol. 67, 702-713 (2015). 
9. Schittenhelm, R. B., Sivaneswaran, S., Lim Kam Sian, T. C., Croft, N. P. \& Purcell, A. W. Human leukocyte antigen (HLA) B27 allotype-specific binding and candidate arthritogenic peptides revealed through heuristic clustering of data-independent acquisition mass spectrometry (DIA-MS) data. Mol. Cell. Proteomics 15, 1867-1876 (2016)

10. Saag, M. et al. High sensitivity of human leukocyte antigen-B $B^{\star 5701}$ as a marker for immunologically confirmed abacavir hypersensitivity in white and black patients. Clin. Infect. Dis. 46, 1111-1118 (2008).

11. Daly, A. K. et al. HLA-B ${ }^{\star 5701}$ genotype is a major determinant of druginduced liver injury due to flucloxacillin. Nat. Genet. 41, 816-819 (2009).

12. Mallal, S. et al. Association between presence of HLA-B ${ }^{\star} 5701$, HLA-DR7, and HLA-DQ3 and hypersensitivity to HIV-1 reverse-transcriptase inhibitor abacavir. Lancet 359, 727-732 (2002).

13. Hung, S.-I. et al. HLA-B ${ }^{\star} 5801$ allele as a genetic marker for severe cutaneous adverse reactions caused by allopurinol. Proc. Natl Acad. Sci. USA 102, 4134-4139 (2005).

14. Bharadwaj, M. et al. Drug hypersensitivity and human leukocyte antigens of the major histocompatibility complex. Annu. Rev. Pharmacol. Toxicol. 52, 401-431 (2012).

15. Illing, P. T. et al. Immune self-reactivity triggered by drug-modified HLApeptide repertoire. Nature 486, 554-558 (2012).

16. Ostrov, D. A. et al. Drug hypersensitivity caused by alteration of the MHCpresented self-peptide repertoire. Proc. Natl Acad. Sci. USA 109, 9959-9964 (2012).

17. Tynan, F. E. et al. A T cell receptor flattens a bulged antigenic peptide presented by a major histocompatibility complex class I molecule. Nat. Immunol. 8, 268-276 (2007).

18. Burrows, J. M. et al. The impact of HLA-B micropolymorphism outside primary peptide anchor pockets on the CTL response to CMV. Eur. J. Immunol. 37, 946-953 (2007).

19. Kloverpris, H. N. et al. A molecular switch in immunodominant HIV-1specific CD8 T-cell epitopes shapes differential HLA-restricted escape. Retrovirology 12, 20 (2015).

20. Park, B., Lee, S., Kim, E. \& Ahn, K. A single polymorphic residue within the peptide-binding cleft of MHC class I molecules determines spectrum of tapasin dependence. J. Immunol. 170, 961-968 (2003).

21. Altfeld, M. et al. Influence of HLA-B57 on clinical presentation and viral control during acute HIV-1 infection. AIDS 17, 2581-2591 (2003).

22. Kaslow, R. A. et al. Influence of combinations of human major histocompatibility complex genes on the course of HIV-1 infection. Nat. Med. 2, 405-411 (1996).

23. Kloverpris, H. N. et al. HLA-B ${ }^{\star} 57$ Micropolymorphism shapes HLA allelespecific epitope immunogenicity, selection pressure, and HIV immune control. J. Virol. 86, 919-929 (2012).

24. Yu, X. G. et al. Mutually exclusive T-cell receptor induction and differential susceptibility to human immunodeficiency virus type 1 mutational escape associated with a two-amino-acid difference between HLA class I subtypes. J. Virol. 81, 1619-1631 (2007).

25. Stewart-Jones, G. B. et al. Structural features underlying T-cell receptor sensitivity to concealed MHC class I micropolymorphisms. Proc. Natl Acad. Sci. USA 109, E3483-E3492 (2012).

26. Abelin, J. G. et al. Mass spectrometry profiling of HLA-associated peptidomes in mono-allelic cells enables more accurate epitope prediction. Immunity 46, 315-326 (2017).

27. Zernich, D. et al. Natural HLA class I polymorphism controls the pathway of antigen presentation and susceptibility to viral evasion. J. Exp. Med. 200, 13-24 (2004)

28. Macdonald, W. A. et al. A naturally selected dimorphism within the HLA-B44 supertype alters class I structure, peptide repertoire, and $\mathrm{T}$ cell recognition. J. Exp. Med. 198, 679-691 (2003).

29. Doxiadis, I. I. N. et al. Association between specific HLA combinations and probability of kidney allograft loss: the taboo concept. Lancet 348, 850-853 (1996).

30. Hilton, H. G. et al. The intergenic recombinant HLA-B ${ }^{\star} 46: 01$ has a distinctive peptidome that includes KIR2DL3 ligands. Cell Rep. 19, 1394-1405 (2017).

31. Colaert, N., Helsens, K., Martens, L., Vandekerckhove, J. \& Gevaert, K. Improved visualization of protein consensus sequences by iceLogo. Nat. Methods 6, 786-787 (2009).

32. Dudek, N. L. et al. Constitutive and inflammatory immunopeptidome of pancreatic $\beta$-cells. Diabetes 61, 3018-3025 (2012)

33. Tan, C. T., Croft, N. P., Dudek, N. L., Williamson, N. A. \& Purcell, A. W. Direct quantitation of MHC-bound peptide epitopes by selected reaction monitoring. Proteomics 11, 2336-2340 (2011).

34. Chessman, D. et al. Human leukocyte antigen class I-restricted activation of $\mathrm{CD} 8+\mathrm{T}$ cells provides the immunogenetic basis of a systemic drug hypersensitivity. Immunity 28, 822-832 (2008)
35. Macdonald, W. A. et al. T cell allorecognition via molecular mimicry. Immunity 31, 897-908 (2009)

36. Mifsud, N. A. et al. Immunodominance hierarchies and gender bias in direct T-CD8-cell alloreactivity. Am. J. Transplant. 8, 121-132 (2008).

37. Bettens, F., Buhler, S. \& Tiercy, J.-M. Allorecognition of HLA-C mismatches by $\mathrm{CD} 8(+) \mathrm{T}$ cells in hematopoietic stem cell transplantation is a complex interplay between mismatched peptide-binding region residues, HLA-C expression, and HLA-DPB1 disparities. Front. Immunol 7, 584 (2016).

38. Gonzalez-Galarza, F. F., Christmas, S., Middleton, D. \& Jones, A. R. Allele frequency net: a database and online repository for immune gene frequencies in worldwide populations. Nucleic Acids Res. 39, D913-D919 (2011).

39. Gonzalez-Galarza, F. F. et al. Allele frequency net 2015 update: new features for HLA epitopes, KIR and disease and HLA adverse drug reaction associations. Nucleic Acids Res. 43, D784-D788 (2015).

40. Barber, L. D. et al. Polymorphism in the alpha(1) helix of the HLA-B heavy chain can have an overriding influence on peptide-binding specificity. $J$. Immunol. 158, 1660-1669 (1997).

41. Falk, K. et al. Peptide motifs of HLA-B58, B60, B61 and B62 molecules. Immunogenetics 41, 165-168 (1995).

42. Rizvi, S. M. et al. Distinct assembly profiles of HLA-B molecules. J. Immunol 192, 4967-4976 (2014).

43. Bailey, A. et al. Selector function of MHC I molecules is determined by protein plasticity. Sci. Rep. 5, 14928 (2015).

44. Tynan, F. E. et al. The immunogenicity of a viral cytotoxic T cell epitope is controlled by its MHC-bound conformation. J. Exp. Med. 202, 1249-1260 (2005).

45. Tynan, F. E. et al. High resolution structures of highly bulged viral Epitopes bound to major histocompatibility complex class I-implications for T-cell receptor engagement and T-cell immunodominance. J. Biol. Chem. 280, 23900-23909 (2005)

46. Pymm, P. et al. MHC-I peptides get out of the groove and enable a novel mechanism of HIV-1 escape. Nat. Struct. Mol. Biol. 24, 387-394 (2017).

47. McMurtrey, C. et al. Toxoplasma gondii peptide ligands open the gate of the HLA class I binding groove. eLife 5, e12556 (2016).

48. Collins, E. J., Garboczi, D. N. \& Wiley, D. C. Three-dimensional structure of a peptide extending from one end of a class I MHC binding site. Nature 371, 626-629 (1994).

49. Fleischhauer, K., Kernan, N. A., O’Reilly, R. J., Dupont, B. \& Yang, S. Y. Bone marrow-allograft rejection by $\mathrm{T}$ lymphocytes recognizing a single amino acid difference in HLA-B44. N. Engl. J. Med. 323, 1818-1822 (1990).

50. Keever, C. A. et al. HLA-B44-directed cytotoxic T cells associated with acute graft-versus-host disease following unrelated bone marrow transplantation. Bone Marrow Transplant. 14, 137-145 (1994).

51. Storkus, W. J., Howell, D. N., Salter, R. D., Dawson, J. R. \& Cresswell, P. NK susceptibility varies inversely with target cell class I HLA antigen expression. J. Immunol. 138, 1657-1659 (1987).

52. Zemmour, J., Little, A. M., Schendel, D. J. \& Parham, P. The HLA-A,B negative mutant cell line C1R expresses a novel HLA-B35 allele, which also has a point mutation in the translation initiation codon. J. Immunol. 148, 1941-1948 (1992)

53. Degli-Esposti, M. A. et al. Characterization of 4AOHW cell line panel including new data for the 10IHW panel. Hum. Immunol. 38, 3-16 (1993).

54. Barnstable, C. J. et al. Production of monoclonal antibodies to group A erythrocytes, HLA and other human cell surface antigens-new tools for genetic analysis. Cell 14, 9-20 (1978).

55. Schittenhelm, R. B., Dudek, N. L., Croft, N. P., Ramarathinam, S. H. \& Purcell A. W. A comprehensive analysis of constitutive naturally processed and presented HLA-C04:01 (Cw4)-specific peptides. Tissue Antigens 83, 174-179 (2014).

56. Lockless, S. W. \& Ranganathan, R. Evolutionarily conserved pathways of energetic connectivity in protein families. Science 286, 295-299 (1999).

57. Mendoza, J. L. et al. Requirements for efficient correction of DeltaF508 CFTR revealed by analyses of evolved sequences. Cell 148, 164-174 (2012).

58. Wickham, H. ggplot2: Elegant Graphics for Data Analysis. (Springer-Verlag, New York, 2009).

59. Lê, S., Josse, J. \& Husson, F. FactoMineR: an R package for multivariate analysis. J. Stat. Softw. 25, 1-18 (2008).

60. RCoreTeam., R. A Language and Environment for Statistical Computing (R Foundation for Statistical Computing, Vienna, Austria, 2016).

61. Schloerke, B. et al. GGally: Extension to 'ggplot2' (The Comprehensive R Archive Network, 2016) https:/github.com/ggobi/ggally.

62. MacLean, B. et al. Skyline: an open source document editor for creating and analyzing targeted proteomics experiments. Bioinformatics 26, 966-968 (2010).

63. Clements, C. S. et al. The production, purification and crystallization of a soluble heterodimeric form of a highly selected T-cell receptor in its unliganded and liganded state. Acta Crystallogr. D Biol. Crystallogr. 58, 2131-2134 (2002) 
64. Collaborative. The CCP4 suite: programs for protein crystallography. Acta Crystallogr. D Biol. Crystallogr. 50, 760-763 (1994).

65. Evans, P. Scaling and assessment of data quality. Acta Crystallogr. D Biol. Crystallogr. 62, 72-82 (2006).

66. Leslie, A. G. W. Recent changes to the MOSFLM package for processing film and image plate data. Joint CCP4 + ESF-EAMCB Newsletter on Protein Crystallography 26, https://www.ccp4.ac.uk/newsletters/No26.pdf, (1992).

67. McCoy, A. J. et al. Phaser crystallographic software. J. Appl. Crystallogr. 40, 658-674 (2007).

68. Emsley, P. \& Cowtan, K. Coot: model-building tools for molecular graphics. Acta Crystallogr. D Biol. Crystallogr. 60, 2126-2132 (2004).

69. Adams, P. D. et al. PHENIX: a comprehensive Python-based system for macromolecular structure solution. Acta Crystallogr. D Biol. Crystallogr. 66, 213-221 (2010).

70. Vizcaino, J. A. et al. 2016 update of the PRIDE database and its related tools. Nucleic Acids Res. 44, D447-D456 (2016).

\section{Acknowledgements}

Thank you to Tracy Josephs for assistance with protocols for the thermal stability experiments. This work was funded by a NHMRC Project grant (1063829) to A.W.P. and J.P.V., and by NIH grant AI22039 to P.P. A.W.P. is supported by a NHMRC Senior Research Fellowship (1044215). P.T.I. was supported by a NHMRC Early Career Fellowship (1072159). J.R. is supported by an Australian Research Council Australian Laureate Fellowship. J.L.M. is supported by NIH award K01CA175127. J.M. was supported by a NHMRC Project Grant (1120467) and Program Grant (1113293).

\section{Author contributions}

P.T.I., A.W.P. and J.P.V. contributed to study design, data collection, data analysis and writing of the manuscript. Ph.P., N.A.M., N.P.C., H.G.H., V.J., A.S.H., J.L.M., N.L.D., P. P., J.M. and J.R. contributed to data collection, data analysis and writing of the manuscript.

\section{Additional information}

Supplementary Information accompanies this paper at https://doi.org/10.1038/s41467018-07109-w.

Competing interests: The authors declare no competing interests.

Reprints and permission information is available online at http://npg.nature.com/ reprintsandpermissions/

Publisher's note: Springer Nature remains neutral with regard to jurisdictional claims in published maps and institutional affiliations.

\begin{abstract}
(c) (1)
Open Access This article is licensed under a Creative Commons Attribution 4.0 International License, which permits use, sharing, adaptation, distribution and reproduction in any medium or format, as long as you give appropriate credit to the original author(s) and the source, provide a link to the Creative Commons license, and indicate if changes were made. The images or other third party material in this article are included in the article's Creative Commons license, unless indicated otherwise in a credit line to the material. If material is not included in the article's Creative Commons license and your intended use is not permitted by statutory regulation or exceeds the permitted use, you will need to obtain permission directly from the copyright holder. To view a copy of this license, visit http://creativecommons.org/ licenses/by/4.0/.
\end{abstract}

(C) The Author(s) 2018 